\title{
Power Sharing and Control Strategy for Provisionally Coupled Microgrid Clusters through an Isolated Power Exchange Network
}

\author{
S.M. Ferdous *, Farhad Shahnia (D) and GM Shafiullah \\ Discipline of Engineering and Energy, Murdoch University, Perth, WA 6150, Australia; \\ F.Shahnia@murdoch.edu.au (F.S.); GM.Shafiullah@murdoch.edu.au (G.S.) \\ * Correspondence: SM.Ferdous@murdoch.edu.au
}

check for updates

Citation: Ferdous, S.M.; Shahnia, F.; Shafiullah, G. Power Sharing and Control Strategy for Provisionally Coupled Microgrid Clusters through an Isolated Power Exchange Network Energies 2021, 14, 7514. https:// doi.org/10.3390/en14227514

Academic Editor: Hartmut Hinz

Received: 18 September 2021

Accepted: 30 October 2021

Published: 10 November 2021

Publisher's Note: MDPI stays neutral with regard to jurisdictional claims in published maps and institutional affiliations.

Copyright: (c) 2021 by the authors. Licensee MDPI, Basel, Switzerland. This article is an open access article distributed under the terms and conditions of the Creative Commons Attribution (CC BY) license (https:// creativecommons.org/licenses/by/ $4.0 /)$.

\begin{abstract}
The two common mechanisms of load-shedding and renewable curtailment can prevent provisional overloading and excessive generation and the subsequent unacceptable voltage and frequency deviation in standalone microgrids (MGs), which makes MGs less resilient and reliable. However, instead of enabling load-shedding or renewable curtailment, such overloading or over-generation problems can be alleviated more efficiently and cost-effectively by provisionally interconnecting the neighboring MGs to exchange power amongst themselves. In such a scheme, the interconnected MGs can supply their local demand, as well as a portion of the demand of the adjacent MGs. In order to implement this strategy, a three-phase ac link can be used as the power exchange network, while each MG is coupled to the link through a back-to-back power electronics converter, in order to maintain the autonomy of each MG if they are eachoperated under different standards. This paper proposes a suitable decentralized power management strategy without a communication link between the MGs to achieve power-sharing amongst them and alleviate unacceptable voltage and frequency deviation along with the required control technique for the power electronic converters, which can be implemented at the primary level based on the measurement of the local parameters only. To this end, one of the converters should always regulate the dc link voltage while the other converter should operate in droop control mode when the MG is healthy and in constant PQ mode when overloaded or over-generating. Suitable status detection and mode transition algorithms and controllers were also developed and are proposed in this paper. The performance of the proposed power exchange and control mechanisms were evaluated and verified via PSIM ${ }^{\circledR}$-based numerical simulation studies. The stability and sensitivity of the proposed power exchange topology are also analyzed against several critical design and operational parameters.
\end{abstract}

Keywords: coupled microgrids; dynamic frequency regulation; overload management; overgeneration control; power exchange link; power-sharing; back-to-back converter control

\section{Introduction}

A microgrid (MG) system is a small-scale electricity grid that consists of dispatchable and non-dispatchable distributed energy resources (DERs) and distributed loads. MGs can feature a central or decentral control mechanism [1-3]. Generally, MGs can operate in grid-connected or off-grid (autonomous) modes. MGs usually operate under droop control in the autonomous mode, through which preferred power-sharing can be achieved amongst its DERs by properly regulating the voltage magnitude and frequency. Thus, the local controllers of droop-controlled DERs will adjust the output power continuously to maintain the MG's voltage magnitude and frequency within the acceptable range and thus ensure its stability [4,5]. The use of islanded MG in remote localities or the regional edge-of-the-grid network is gaining popularity due to its economic aspects and advantages. Several studies have shown that employing autonomous MGs is a feasible solution for 
the electrification of remote areas as it can significantly reduce the levelized cost of power generation [6-8].

\subsection{Background and Literature Review}

MGs are more economical alternatives for the electrification of remote and regional areas. Hence, an autonomous MG, mostly dominated by renewable energy sources along with some diesel/gas-driven synchronous generators, can be employed permanently in such areas. Its high ongoing fuel costs and transportation impose further challenges on the operation of these MGs. On the other hand, overloading or excessive generation can occur in these MGs because of the variability and intermittency of the renewable energies, despite the uncertain considerations in system planning $[9,10]$. The temporary deficiency in the power generation capability of an MG versus its demand is referred to as overloading. This can be addressed by load-shedding for the voltage frequency and magnitude's return to acceptable limits. On the other hand, over-generation refers to a situation in which the MG experiences high generation and an excess of power through one or more of its non-dispatchable DERs. Curtailing such renewable energy resources is a solution to such conditions. However, both load-shedding and curtailing renewable sources are uneconomical and undesirable, which reduces the reliability and resilience of the system. Proper risk-based planning can help to prevent such scenarios by overdesigning and oversizing DGs and/or employing energy storage to address the overloading and excessive generation and the subsequent voltage frequency and magnitude deviations. However, this increases initial and ongoing costs $[11,12]$. Thus, $[13,14]$ have proposed another alternative that involves temporarily interconnecting the adjacent MGs in states that allow them to help each other to holding the voltage frequency and magnitude and the MG's stability. Notably, the interconnection is not to a grid but to another neighboring MG, which is also operating autonomously. Therefore, the resulting interconnected autonomous MGs forms a group of coupled microgrids (CMGs). Refs. $[3,15,16]$ have deliberated the model and operation of CMGs, considering the availability of a power market and communication infrastructure.

It is expected that in the future, a remote area will be made up of multiple adjacent MGs. If so, overloading and excessive generation problems can be addressed effectively by a suitable coupling of adjacent MGs $[16,17]$. CMGs can also enhance overall system reliability $[18,19]$.

Conventional circuit breakers, interconnecting static switches [20], or back-to-back power electronics-based converters [21-23] can be building components of the interconnecting physical link between the MGs. It should be noted that, as the control technique of every MG can be dissimilar, proper isolation is essential amongst the MGs for the independent and autonomous operation of every MG [22-24]. In this regard, the back-to-back power electronic converter topology is highly preferred [24,25].

An analysis of CMG architectures is presented in detail in [16,17]. Ref. [18] studied the optimal control of a utility grid-connected MG to form a CMG, while load-sharing through interactive control of a CMG for wide system stability is discussed in [19]. Dynamic power-sharing between two autonomous back-to-back connected MGs is studied in $[13,14,26,27]$. The stability assessment of a multi-inverter MG is presented in [28]. An appropriate electrical framework and protocol are essential for power-sharing through an interconnected system of MGs [20]. A coordinated power exchange strategy among MGs, along with their local energy storage system is demonstrated in [20,29]. Most of the existing studies on CMGs are primarily focused on optimization, stability assessment, enhancing fault ride-through capability, power management, topology, and network evaluation, assuming a direct physical ac interconnection between the MGs forming a CMG. As an example, [30-32] focused on a distributed control approach for CMGs and proposed effective approaches for optimized power-sharing amongst the neighboring MGs within a CMG. 
On the other hand, power electronic converter-interfaced CMG network studies are mostly focused on the coupling of two MGs using a back-to-back converter [13,14,26,27,29] and do not address the problem of over-generation. Ref $[15,33]$ demonstrate the operation of three MGs using common dc power lines in the presence of a communication linkbased tertiary/central controller. The decentralized control of the CMG network using ac interconnecting lines is proposed in [23-25]. A comparative analysis of different CMG topologies using ac/dc links is studied in [34].

Creating power exchange among multiple MGs requires a predefined coordinated control mechanism. Ref [24] presented a mechanism to couple multiple MGs to form CMG using single-phase ac lines. The purpose of using a single-phase power exchange link is to reduce the number of converter components and transmission lines in the CMG network to make the system more economical. However, the line power loss is = three-to-four times higher in a single-phase link than that of a three-phase link for the same operating conditions. Furthermore, the power quality is poorer as single-phase instantaneous power is oscillatory in nature. Hence, the three-phase power exchange link is superior in every aspect compared to the single-phase link unless a very small amount of power is required to be exchanged within the CMG network through short interconnecting lines. Although the number of components and power lines require for the three-phase link is higher, the power quality and performance are superior and produce significantly lower line loss, thus making the system more efficient. At the same time, the three-phase network exhibits larger system damping and, hence, a better stability margin, as can be seen from the stability analysis.

On the other hand, CMGs formed using dc interconnecting lines outperform any types of ac links in terms of technical and economic aspects. However, there are several critical issues with dc power exchange links, such as the lack of proper standards and guidelines for the protection scheme, expensive protection equipment, a larger fault current level, arching during fault current interruption due to the absence of natural zero current crossings, lower fault ride-through capability [35-37], circulating current in the network due to unequal line resistance [38,39], and inaccurate and less efficient power-sharing due to the droop control technique [24]. Furthermore, the standard and infrastructure for ac power transmission and distribution systems are well established, and most of the commercially available equipment is ac network-based which makes most of the network operators to prefer ac transmission systems over dc. Considering the cost and complexity of the protection scheme, the dc interconnecting link is more suitable when the distance between the MGs is longer. However, as the distance between the MGs is increased (i.e., the line resistance is increased), the property of power-sharing based on the droop control technique deteriorates and eventually diminishes. At the same time, the increased value of the line resistance makes the CMG network's performance sluggish [24]. Furthermore, unequal line resistances can cause circulating current inside the CMG network [38]. However, these problems can be addressed using the technique discussed in [39], although the performance is not as satisfactory as with the ac droop control technique. In this paper, where a three-phase ac interconnecting link is proposed to form the CMG network, a modified virtual impedance-based angle-active power and voltage-reactive power droop control technique is employed that can successfully address all the aforementioned problems, and the relevant results are presented in the sensitivity analysis section of the paper. Hence, it can be concluded that the performances of a CMG network formed using either three-phase ac or dc interconnecting lines are comparable in terms of different technical and economic aspects and, thus, a proper techno-economical evaluation and optimization is required before selecting the most suitable topology, based on the type of MGs to be interconnected, the amount of exchanged power, the duration and intervals at which power is to be exchanged, the protection scheme, and, finally, the distance between them. A comparative review of ac and dc technology used in MG application can be found in [35,36]. It was discussed in [35] that, although dc systems are more advantageous in several aspects in theory considering the present power transmission 
infrastructure, commercially available protection equipment, technical constraints, network standards, and guidelines, ac systems are still more economical.

\subsection{Contribution and Organization}

This study focused on a CMG consisting of $N$ arbitrary MGs with an existing 3phase ac interlinking line between them. Figure 1 illustrates a generic arrangement of a CMG. CMG networks can couple and share power amongst themselves temporarily (during a power shortfall or surplus) while the interconnection among them is produced via back-to-back power electronic converters and a three-phase ac line (see Figure 1b). At the same time, a back-to-back converter interface also ensures isolation among the MGs within a CMG network and, thus, enables the MGs to retain their autonomy by allowing them to operate any frequency and voltage level as per their network operator's standard. A decentralized (communication-free) power management strategy along with appropriate control principles for back-to-back power electronic converters have been proposed that enable power exchange amongst $N$ autonomous MGs during overloading or over-generation. The communication-free feature enables the application of the proposal on remote area MGs, which are generally preferred due to their low investment cost. The approach can also be used as a backup or contingency mechanism in case of communication link failure, where the CMG network is monitored with a central controller with data communication. The efficacy of the proposed mechanisms is evaluated and verified through simulation studies using PSIM ${ }^{\circledR}$. Finally, the stability and sensitivity of the proposal are studied for the key design and operational variables.

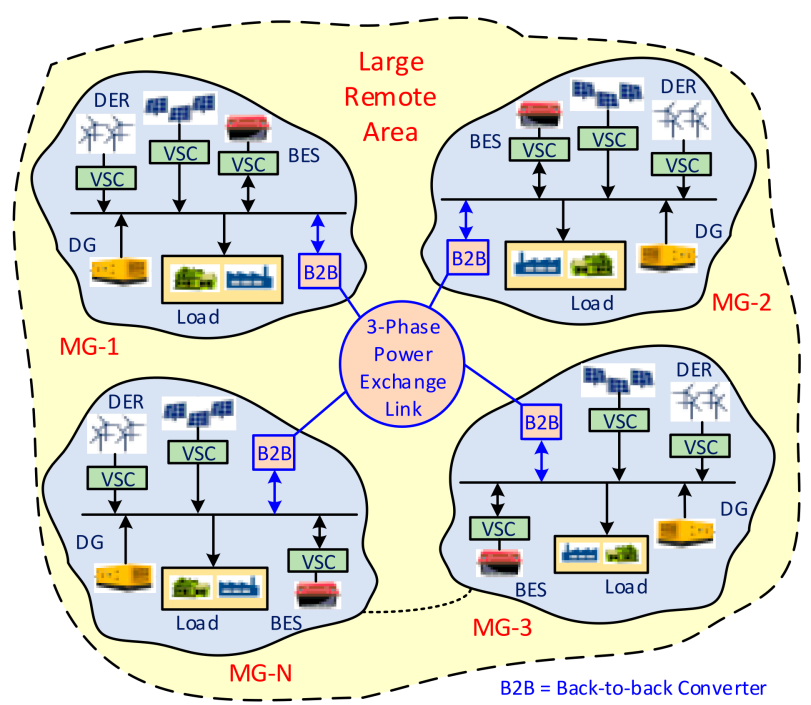

(a)

Converter Topology

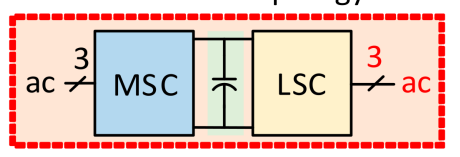

(b)

Figure 1. Schematic of CMG networks, (a) MG structure and their interconnection with the power exchange link, (b) back-to-back three-phase converter topology.

It should be highlighted that this paper does not propose building a three-phase ac interlinking line for new CMGs. The proposal of the paper is a communication-free power management strategy achieved via back-to-back power electronic converters when the three-phase ac links are present. For non-existing interlinking lines, a suitable technoeconomic feasibility study is required first to evaluate and recommend either a dc-link with 
a single converter or a three-phase ac link with back-to-back converters, depending on the power demand and distances of the MGs from each other. The power management and protection aspect of such dc systems would be then different [22,33].

The key contributions of this paper to the research field can be summarized as:

- An effective power exchange strategy to alleviate overload and over-generation problems in autonomous/islanded MGs by temporarily connecting them via a common three-phase power exchange link, in order to retain the desired voltage and frequency level and, thus, enhance their reliability, resilience, and stability.

- A decentralized control mechanism to exchange power among the MGs within the CMG network using only local frequency measurement with no data communication. Such a technique can be expanded to connect any number of MGs with different voltages, frequencies, and operational standards.

- Proper power-sharing amongst the MGs by employing a suitable droop control technique.

The remainder of the paper is organized as follows: Section 2 discusses the proposed structure for the power exchange strategy of the CMG network, while the structure and control of three-phase back-to-back power electronic converter under different modes of operation are discussed in Section 3. The performance of the proposed power exchange strategy is evaluated and demonstrated by time-domain simulation-based case studies in Section 4. The stability and sensitivity analysis of the CMG network are discussed in Sections 5 and 6, respectively. Finally, the key findings of the research are summarized in Section 7. The Appendix A at the end of the paper provides the technical data considered in the numerical studies in the paper.

\section{CMG Structure and Operation}

Consider the system of Figure 1a with $N$ coupled MGs via back-to-back converters (see Figure 1b) and a three-phase ac link. Each MG consists of multiple loads and DERs. At the output of each droop-controlled DER, the voltage frequency and magnitude are determined from

$$
\begin{gathered}
f_{\mathrm{MG}}=f_{\max }-m_{i} P_{i} \\
V=V_{\max }-n_{i} Q_{i}
\end{gathered}
$$

where $m_{i}$ and $n_{i}$ are the droop coefficients of the $i^{\text {th }}$ DER, and derived from

$$
\begin{gathered}
m_{i}=\left(f_{\max }-f_{\min }\right) / P_{i}^{\max } \\
n_{i}=\left(V_{\max }-V_{\min }\right) / 2 Q_{i}^{\max }
\end{gathered}
$$

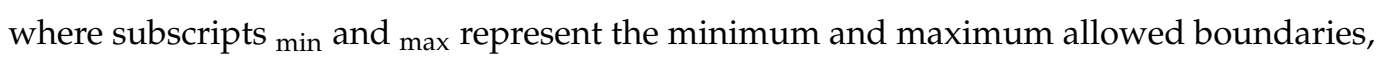
while $Q_{i}$ and $P_{i}$ are the reactive and active powers injected by each DER. All the DERs within an MG feature similar $\Delta f=f_{\max }-f_{\min }$ and $\Delta V=V_{\max }-V_{\min }$; nevertheless, these values can differ from each other in the neighboring MGs. This is one of the key issues that make the operational standards in the neighboring MGs different from each other. The structure and operation of DERs are discussed in [40] and not repeated here.

The adjacent MGs are coupled through 3-phase ac interconnecting power lines and back-to-back power electronics-based converters (Figure 1b). Let us denote the converter connected to the MG as the microgrid-side converter (MSC) and the other converter as the line-side converter (LSC). They are both voltage source converters connected back-to-back through a common dc link. An LCL filter is between each converter and the ac power lines to restrict the undesired switching harmonics. Figure 2 shows the structure of the converters and their controllers. 


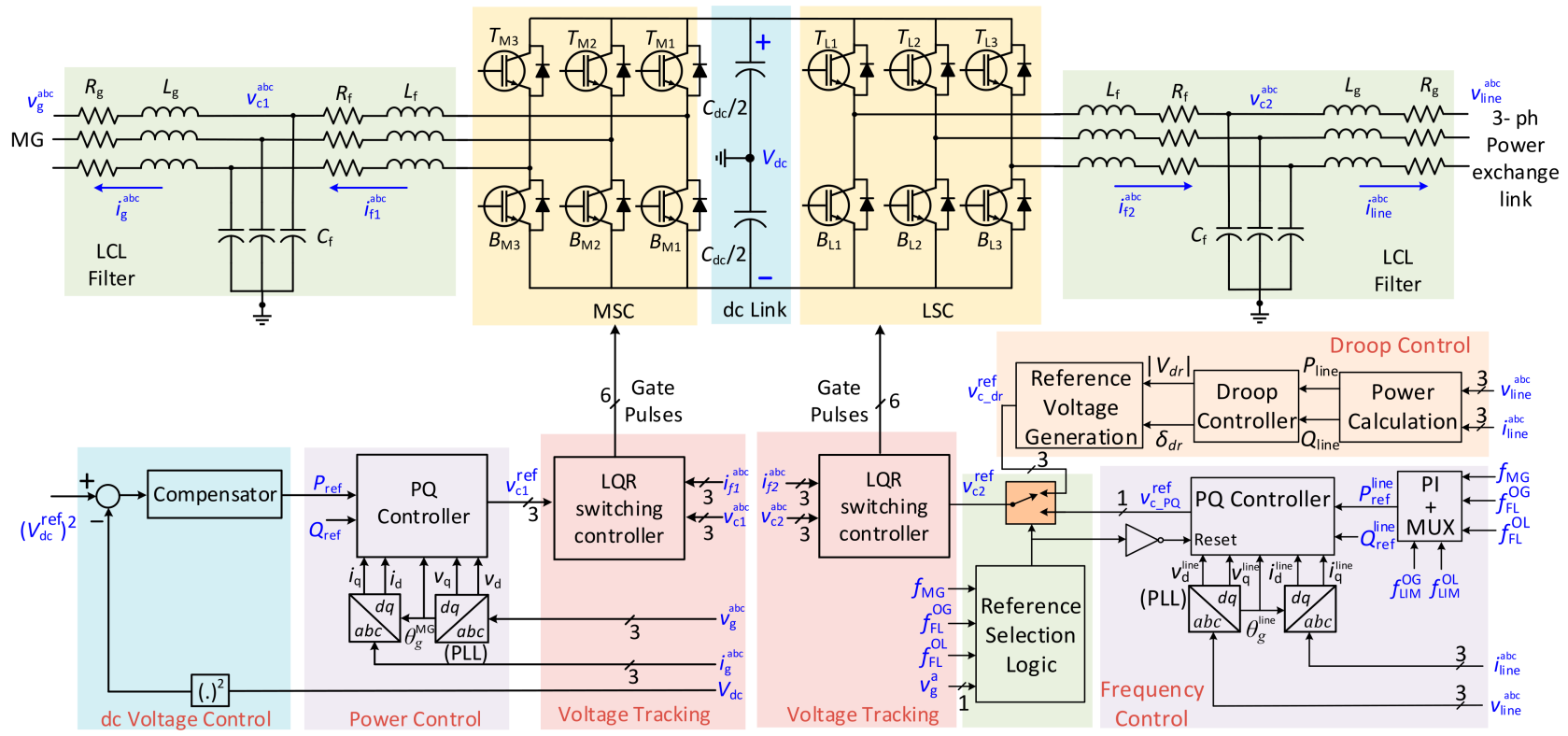

Figure 2. Assumed structure for MSC and LSC connection topology with power exchange lines and their closed-loop controllers.

By monitoring the frequency of each MG, proper power-sharing can be produced amongst the MGs during excessive-generation/overloading scenarios. The frequency of an MG decreases as the demand of the MG increases, and vice versa. This unique feature of droop-controlled MGs can indicate a power deficiency or surplus in an MG. As such, the requirement of a centralized controller or a communication link can be eliminated. The proposed mechanism can even operate as a backup system for a centrally controlled MG as a contingency or in the event of communication link failure.

The participation of MGs in forming the CMG is achieved based on a predefined framework, as the inclusion of all the neighboring MGs in the CMG network may make the system unstable. In this study, the CMG formation depends on the loading level of each MG, which is determined by measuring the MGs' frequencies. As such, the MGs are categorized into three distinct types, namely healthy MG (HMG), floating MG (FMG), and problem MG (PMG).

An MG operating in its nominal condition (within the required frequency and voltage range) is flagged as HMG and participates in forming the CMG. An excessively generating or overloaded MG is referred to as PMG, which seeks support from one or more neighboring HMGs to either export or import power, in order to operate within its required voltage and frequency range.

On the other hand, an MG is flagged as FMG if its loading condition is such that it is very likely to become a PMG. In other words, the FMG's frequency is in the proximity of the boundary of maximum or minimum limits and, hence, it should not participate in the formation of the CMG along with other HMGs.

Let us consider the diagram of Figure 3 and the proposed Algorithm 1, to achieve the operation of such a system. Referring to Figure $3, f_{\mathrm{MG}}$ is the dynamic frequency value of the MG; $f_{\mathrm{FL}}^{\mathrm{OL}}$ and $f_{\mathrm{FL}}^{\mathrm{OG}}$ are the two boundary frequencies, beyond which overloading and excessive generation begin, respectively. Parameters $f_{\mathrm{LIM}}^{\mathrm{OL}}$ and $f_{\mathrm{LIM}}^{\mathrm{OG}}$ are the minimum and maximum allowable frequency within the acceptable limit of the MG, respectively. $f_{\max }$ is the no-load frequency and $f_{\min }$ is the minimum frequency that makes the MG unstable due to excessive loading. An HMG is attained when $f_{\mathrm{FL}}^{\mathrm{OL}}<f_{\mathrm{MG}}<f_{\mathrm{FL}}^{\mathrm{OG}}$. An FMG may be attained in two different conditions: when $f_{\mathrm{LIM}}^{\mathrm{OL}}<f_{\mathrm{MG}}<f_{\mathrm{FL}}^{\mathrm{OL}}$ (increasing demand) or $f_{\mathrm{FL}}^{\mathrm{OG}}<f_{\mathrm{MG}}<f_{\mathrm{LIM}}^{\mathrm{OG}}$ (decreasing demand). Similarly, two conditions; i.e., when $f_{\mathrm{MG}}<f_{\mathrm{LIM}}^{\mathrm{OL}}$ (overloaded) or $f_{\mathrm{MG}}>f_{\mathrm{LIM}}^{\mathrm{OG}}$ (excessive generation) can result in a PMG. 
Algorithm 1: MG status detection and LSC mode of operation.

1. Measure $f_{\mathrm{MG}}$

while $f_{\mathrm{FL}}^{\mathrm{OL}} \leq f_{\mathrm{MG}} \leq f_{\mathrm{FL}}^{\mathrm{OG}}$

2. $\quad$ Flag: HMG (nominal operation)

L SC operates in Droop Control Mode

3. else

4.

if $f_{\mathrm{MG}}>f_{\mathrm{FL}}^{\mathrm{OG}}$

Delay $t_{r}(\mathrm{~ms})$

if $f_{\mathrm{MG}}>f_{\mathrm{LIM}}^{\mathrm{OG}}$

Delay $t_{c}(\mathrm{~ms})$

Flag: PMG (over-gen eration)

L SC operates in PQ Control Mode

(Export Power)

5.

OGFC activated

else

Flag: FMG (over-g en eration)

L SC operates in PQ Control Mode

(No power sharing)

6.

end

else

Delay $t_{r}(\mathrm{~ms})$

if $f_{\mathrm{MG}}<f_{\mathrm{LIM}}^{\mathrm{OL}}$

Delay $t_{c}(\mathrm{~ms})$

Flag: PMG (overload)

L SC operates in PQ Control Mode

(Import Power)

OLFC Activated

7.

else

Flag: FMG (overload)

L SC operates in PQ Control Mode

(No power sharing)

end

end

end

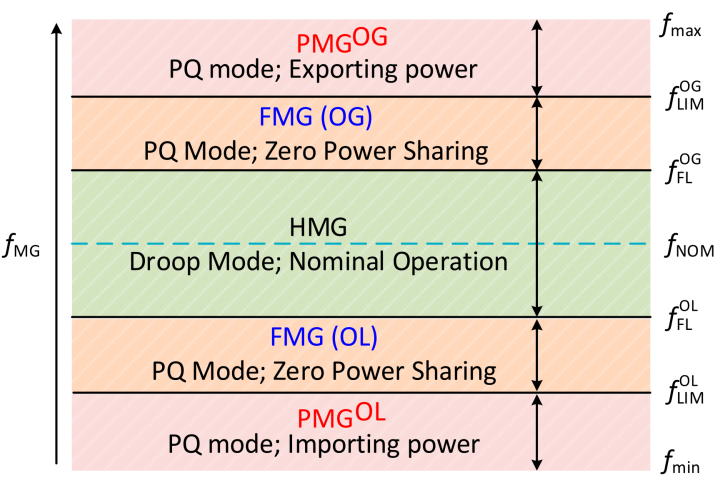

Figure 3. MG status and its different operating modes based on its frequency range. 


\section{Converter Topologies and Control Mechanism}

Referring to Figure 3 and Algorithm 1, the LSC operates in two different modes, depending on the frequency level of the respective MG. The corresponding LSCs of all the available HMGs operate in droop control mode to form the CMG network. The corresponding LSCs of the PMGs and FMGs are required to operate in constant PQ control mode to export or import the required amount of power through the network. The CMG network is assumed to be a three-phase ac interconnecting line with back-to-back connected power electronic converters. In this paper, both the MSC and LSC are assumed to be threephase, three-leg VSC using IGBTs or MOSFETs. Each VSC is connected to its point of common coupling through a three-phase LCL filter. The structures of MSC and LSC are shown schematically in Figure 2. It may be noted here that any other three-phase VSC topologies can also be implemented instead of the topologies considered here.

\subsection{MSC Control}

The main function of MSC is to regulate the dc-link voltage of $V_{\mathrm{dc}}$ at the reference value of $V_{\mathrm{dc}}^{\text {ref. }}$. This is valid irrespective of the MG's status (i.e., HMG, FMG or PMG). The dc-link of the MSC facilitates the exchange of the appropriate level of power with the MG through proper voltage regulation, such that the dc-link voltage remains constant. This can be achieved via a closed-loop control mechanism (i.e., the outermost control loop of the MSC controller in Figure 2) to obtain the reference of the active power $\left(P_{\text {ref }}\right)$ that needs to be drawn from or injected into the MG to keep $V_{\mathrm{dc}}$ regulated at the reference value. The MSC is not expected to exchange any reactive power with the MG and hence, the reactive power $\left(Q_{\text {ref }}\right)$ reference for it is set to zero. Based on these two references, the PQ controller determines the three-phase reference voltage $\left(v_{\mathrm{C}}^{\text {ref }}\right)$ across the capacitor $C_{\mathrm{f}}$ of LCL filter of the MSC. The innermost control loop of MSC in Figure 2 is the voltage tracking and switching control block. The linear quadratic regulator (LQR) is used to achieve robust and optimum performance in tracking the sinusoidal reference voltage, as discussed in [40].

\subsubsection{Voltage Tracking and Switching Control}

The voltage tracking and switching control of the MSC are implemented based on the LCL filter dynamics. The filter inductance, $L_{\mathrm{f}}$ and filter capacitor, $C_{\mathrm{f}}$ of the LCL filter comprises the assumed system dynamics, which operates as the innermost loop of the closed-loop control mechanism of MSC. The dynamics of the LCL filter can be represented in the state-space form by

$$
\dot{x}=A x+B_{1} u_{\mathrm{c}}+B_{2} i_{\mathrm{g}}
$$

where $A=\left[\begin{array}{cc}0 & 1 / C_{\mathrm{f}} \\ -1 / L_{\mathrm{f}} & -R_{\mathrm{f}} / L_{\mathrm{f}}\end{array}\right], \boldsymbol{B}_{\mathbf{1}}=\left[\begin{array}{c}0 \\ V_{\mathrm{dc}} / 2 L_{\mathrm{f}}\end{array}\right], \boldsymbol{B}_{\mathbf{2}}=\left[\begin{array}{c}-1 / C_{\mathrm{f}} \\ 0\end{array}\right]$ and $\boldsymbol{x}=\left[v_{\mathrm{c}} i_{\mathrm{f}}\right]^{T}$ while $u_{c}$ is the switching control function, $i_{g}$ is the coupling inductor current that can be considered as system disturbance and ${ }^{T}$ is the transpose operator. The current, $i_{\mathrm{f}}$, should only feature the low-frequency component (i.e., $50 \mathrm{~Hz}$ ) and all the high-frequency switching components should be filtered out. Hence, the feedback control structure introduces a high-pass filter (with a cut-off frequency of $\omega_{c}$ ) to extract the high-frequency components of $i_{\mathrm{f}}$ as denoted by $\widetilde{i_{\mathrm{f}}}$. Thus, (3) can be rewritten as

$$
\dot{x}_{\mathrm{c}}=A_{\mathrm{c}} x_{\mathrm{c}}+B_{\mathrm{c}} u_{\mathrm{c}}
$$

where $A_{\mathrm{c}}=\left[\begin{array}{ccc}0 & 1 / C_{\mathrm{f}} & 0 \\ -1 / L_{\mathrm{f}} & -R_{\mathrm{f}} / L_{\mathrm{f}} & 0 \\ -1 / L_{\mathrm{f}} & -R_{\mathrm{f}} / L_{\mathrm{f}} & -\omega_{\mathrm{c}}\end{array}\right], \boldsymbol{B}_{\mathrm{c}}=\left[\begin{array}{c}0 \\ V_{\mathrm{dc}} / 2 L_{\mathrm{f}} \\ V_{\mathrm{dc}} / 2 L_{\mathrm{f}}\end{array}\right]$ and $x_{\mathrm{c}}=\left[v_{\mathrm{c}} i_{\mathrm{f}} \widetilde{i}_{\mathrm{f}}\right]^{T}$.

An appropriate control law using state feedback along with a reference input (which, in this case, is the reference filter capacitor voltage, $v_{\mathrm{c}}^{\text {ref }}$ ) can be expressed in the form of

$$
u_{\mathrm{c}}=k_{1}\left(v_{\mathrm{c}}^{\mathrm{ref}}-v_{\mathrm{c}}\right)-k_{2} i_{\mathrm{f}}-k_{3} \widetilde{i}_{\mathrm{f}}=-\boldsymbol{K} \dot{x}_{\mathrm{c}}+k_{1} v_{\mathrm{c}}^{\mathrm{ref}}
$$


where $\boldsymbol{K}=\left[\begin{array}{lll}k_{1} & k_{2} & k_{2}\end{array}\right]$ is the state-feedback gain matrix, in which $k_{1}, k_{2}$ and $k_{3}$ are optimally determined by minimizing an appropriate cost function using an LQR. Based on the optimization method, a high-performance switching controller can be implemented with a larger bandwidth to accurately track the low-frequency sinusoidal signal (i.e., $50 \mathrm{~Hz}$ ) with zero steady-state error and phase delay. Therefore, (4) can be rewritten as

$$
\dot{x}_{\mathrm{c}}=A_{\mathrm{cl}} x_{\mathrm{c}}+\boldsymbol{B}_{\mathrm{cl}} v_{\mathrm{c}}^{\mathrm{ref}}
$$

where $\boldsymbol{A}_{\mathrm{cl}}=\boldsymbol{A}_{\mathrm{c}}-\boldsymbol{B}_{\mathrm{c}} \boldsymbol{K}$ and $\boldsymbol{B}_{\mathrm{cl}}=k_{1} \boldsymbol{B}_{\mathrm{c}}$. The implemented controller offers infinite gain and phase margin and is thus robustly stable. The switching of the MOSFET/IGBT can be implemented through a suitable hysteresis controller with an adequately small band (e.g., $h= \pm 10^{-4}$ ). The block diagram of such an LQR switching controller is shown in Figure 4 .

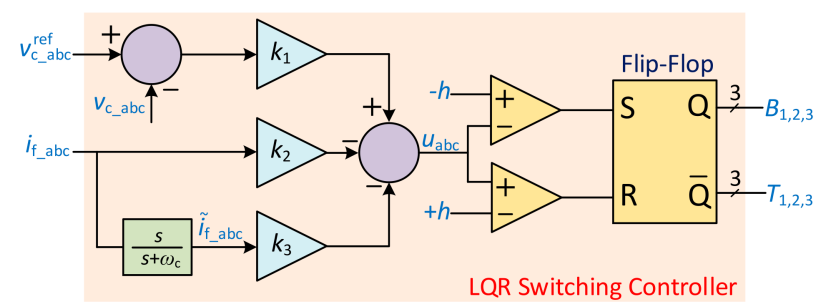

Figure 4. LQR-based switching and voltage tracking.

\subsubsection{Power Control}

The next control loop is to determine the appropriate reference voltage across the capacitor, $C_{\mathrm{f}}$, of the LCL filter by regulating the active and reactive power. For this purpose, the conventional direct-quadrature $(\mathrm{dq})$ axis close loop power controller (i.e., PQ controller) is implemented. The PQ controller decouples the active and reactive powers and can be controlled independently. The active and reactive powers are regulated by controlling the d-axis current $i_{\mathrm{d}}$ and q-axis current $i_{\mathrm{q}}$, respectively. Hence, the PQ controller is also known as the current controller. The controller is made of two proportional-integral (PI) controllers that are responsible for producing $v_{\mathrm{d}}^{\text {ref }}$ and $v_{\mathrm{q}}^{\text {ref }}$ (the reference voltages of the $\mathrm{d}$ and $q$ axis). Next, the equivalent three-phase ac reference voltage for these two voltages $\left(v_{\mathrm{C}}^{\text {ref }}\right.$ across the filter capacitor, $\left.C_{\mathrm{f}}\right)$ is calculated using the grid angle $\theta_{\mathrm{g}}^{\mathrm{MG}}$, as obtained through a synchronous reference frame phase-locked loop. The dynamics of the output $\mathrm{R}-\mathrm{L}$ branch of the LCL filter, comprised of coupling inductance, $L_{\mathrm{g}}$, and resistance, $R_{\mathrm{g}}$, are considered to design and tune the two PI controllers via the pole-zero cancellation technique [41], which feature transfer functions in the form of

$$
C_{\mathrm{PI}}(s)=\frac{K_{\mathrm{c}}\left(s T_{\mathrm{c}}+1\right)}{s T_{\mathrm{C}}}
$$

where $T_{\mathrm{c}}=L_{\mathrm{g}} / R_{\mathrm{g}}$ and $K_{\mathrm{c}}=2 \pi f_{\mathrm{BW}} L_{\mathrm{g}}$ while $f_{\mathrm{BW}}$ (the closed-loop controller's bandwidth) conventionally needs to be at least 10 times smaller than the inner voltage tracking loop's bandwidth, and hence, the inner loop can be considered as a block with a unity gain when the PI controllers of the PQ controller are tuned. In this design, $f_{\mathrm{BW}}$ is chosen to be 1000 times faster than the voltage tracking loop to ensure no overlap in the bandwidth of the control loops and proper sinusoidal voltage tracking at $50 \mathrm{~Hz}$. The closed-loop transfer function of the PQ controller is then given by

$$
G_{\mathrm{c}}(s)=\frac{i_{\mathrm{dq}}^{\mathrm{ref}}}{i_{\mathrm{dq}}}=\frac{1}{s \tau_{\mathrm{c}}+1}=\frac{P_{\mathrm{ref}}}{P_{\mathrm{s}}}
$$

where $\tau_{c}=L_{\mathrm{g}} / K_{c}$ is the time constant of the current controller, $P_{\text {ref }}$ is the reference power and $P_{\mathrm{S}}$ is the active power output of the converter. It should be noted here that $P_{\text {ref }}$ is 
generated through the outermost control loop i.e., the dc-link voltage controller. The assumed close-loop PQ controller for MSC is shown in Figure 5.

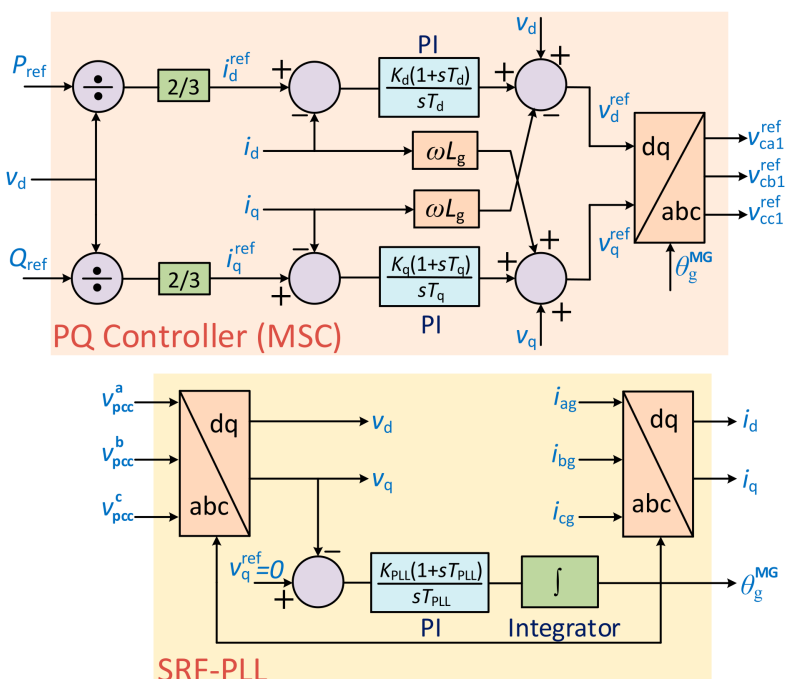

Figure 5. Block diagram of PQ controller for MSC.

\subsubsection{DC-Link Voltage Control}

The dc-link voltage controller is the outermost loop of the control structure. The dynamics of the voltage across the dc-link capacitor, $V_{\mathrm{dc}}$, against the output power of the converter, $P_{\mathrm{s}}$, can be given in terms of a transfer function of $[41,42]$

$$
G_{\mathrm{dc}}(s)=\frac{V_{\mathrm{dc}}^{2}}{P_{\mathrm{s}}}=\left(\frac{-2}{C_{\mathrm{dc}}}\right) \frac{\left(s \tau_{\mathrm{dc}}+1\right)}{s}
$$

where $\tau_{\mathrm{dc}}=2\left(L_{\mathrm{f}}+L_{\mathrm{g}}\right) P_{\mathrm{so}} / 3 V_{\mathrm{do}}^{2}$. The transfer function of $G_{\mathrm{dc}}(s)$ is a linearized smallsignal model, where $P_{\mathrm{so}}$ is the converter's steady-state output power and $V_{\mathrm{do}}$ is the d-axis steady-state voltage at the point of common coupling of the converter to the MG. It is a non-minimum phase system with a right half plane zero, whose location depends on the steady-state value of $P_{\mathrm{so}}$ and $V_{\mathrm{do}}$. If these two parameters are varied, then the controller needs to be redesigned to ensure the required stability margin. In other words, the controllers are designed to exchange rated power at a specific voltage level; hence, the exchanged power through the dc-link should not exceed its maximum limit. A type-2 controller can be designed to regulate the dc-link voltage with the required gain and phase margin, with a transfer function of

$$
C_{\mathrm{dc}}(s)=\frac{K_{\mathrm{dc}}\left(s+\omega_{\mathrm{z}}\right)}{s\left(s+\omega_{\mathrm{p}}\right)}
$$

Using the K-factor method, such a controller can be designed [43]. The closed-loop control system of the dc-link voltage can be achieved as presented in Figure 6. It should be noted here that, while regulating the dc-link voltage, the reference power of $P_{\text {ref }}$ in (8) is $P_{\mathrm{dc}}$ (i.e., the power that needs to be exchanged bi-directionally to keep the dc-link voltage fixed to its reference value) as can be seen in Figure 6. As the voltage tracking loop is made almost 1000 times faster than the power control loop, the overall system dynamics of the dc-link voltage can be assumed as

$$
G_{\mathrm{OL}}(s)=G_{\mathrm{c}}(s) G_{\mathrm{dc}}(s)=\left(\frac{-2}{C_{\mathrm{dc}}}\right) \frac{\left(s \tau_{\mathrm{dc}}+1\right)}{s\left(s \tau_{\mathrm{c}}+1\right)}
$$




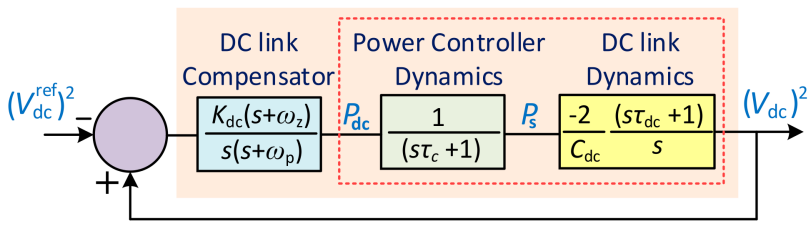

Figure 6. Block diagram of DC-link controller for MSC.

Hence, $G_{\mathrm{OL}}(s)$ is the open-loop transfer function assumed to apply the K-factor method. The steps for designing the controller using this method are discussed in detail in $[42,43]$. The close loop frequency responses of all the three control loops are shown in Figure 7. The close loop bandwidths of the voltage tracking, power, and dc-link controller are $318 \mathrm{kHz}, 300 \mathrm{~Hz}$, and $20 \mathrm{~Hz}$, respectively.

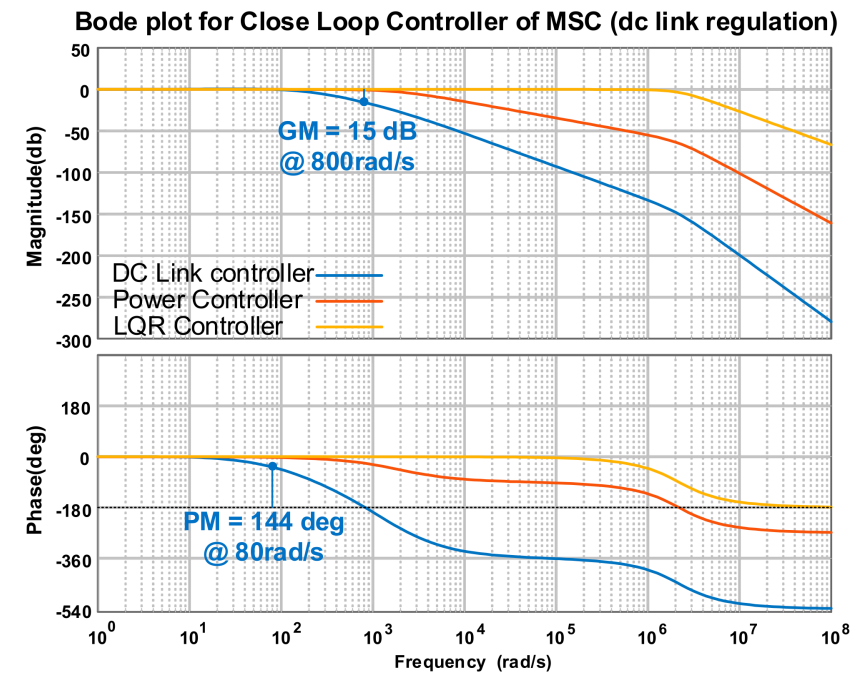

Figure 7. Frequency response plots of the control loops for the MSC.

\subsection{LSC Control}

The dc-link is connected to the interconnecting lines via the LSC. Depending on the status of the MGs, the LSC can work in two operation modes. When the MG is an HMG, the LSC functions under droop control to produce the required power-sharing amongst the HMGs. On the other hand, when the MG becomes FMG or PMG, the LSC converts its operation mode to constant PQ control for absorbing the required power from or injecting it into the interconnecting lines. To produce this change, a reference selector continuously monitors the frequency of the MGs. The required logic controller can be seen in Figure 2.

\subsubsection{HMG Operation (Droop Control Mode)}

The LSCs of all the MGs operate in droop control mode when all the MGs are HMGs. A voltage-angle droop control was employed (in contrast with the voltage-frequency droop of (1)), so that the voltage frequency observed at the interconnecting lines is fixed at the desired value (e.g., $50 \mathrm{~Hz}$ ). This is in order to enable the transition from the PQ to droop control mode (i.e., PMG/FMG becomes an HMG). Otherwise, a transition cannot occur under the frequency droop, as the voltages at the output of the LSC of all the HMGs are of the same frequency; hence, synchronization is not possible in such a situation.

The angle and voltage droop equations for the LSC of $k^{\text {th }}$ MG can be written as $[44,45]$.

$$
\begin{gathered}
\delta_{k}=\delta_{\mathrm{o}}-m_{\mathrm{MG}-k} P_{\text {line }} \\
V_{k}=V_{\max }-n_{\mathrm{MG}-k} Q_{\text {line }}
\end{gathered}
$$


where $m_{\mathrm{MG}-k}$ and $n_{\mathrm{MG}-k}$ are the droop coefficients for the LSC of MG- $k$, calculated from

$$
\begin{gathered}
m_{\mathrm{MG}-k}=\left(\delta_{\max }-\delta_{\min }\right) / P_{\text {line }}^{\max } \\
n_{\mathrm{MG}-k}=\left(V_{\max }-V_{\min }\right) / 2 Q_{\text {line }}^{\max }
\end{gathered}
$$

in which subscript min and max represents the minimum and maximum allowable limits for angle and voltage, while $P_{\text {line }}^{\max }$ and $Q_{\text {line }}^{\max }$ are the maximum active and reactive powers injected/absorbed by each MG to the interconnecting lines. All the LSCs feature similar $\Delta \delta=\delta_{\max }-\delta_{\min }$ and $\Delta V=V_{\max }-V_{\min }$. It should be mentioned here that the transition from $\mathrm{PQ}$ to droop mode cannot be achieved using the frequency-voltage droop because, when all the MGs become HMG with no exchange of power through the interconnecting lines, the voltages at the output of the LSCs operate at the same frequency. Thus, synchronization among the LSCs is not possible in this situation without a centralized controller backed up by a data communication link. The decentralized control scheme works only through the angle-voltage droop control technique. However, the conventional angle-voltage droop control technique cannot ensure the desired power-sharing among the HMGs unless a modified angle droop [44] mechanism is implemented using the virtual impedance method. To implement the virtual impedance-based modified angle droop, (12) needs to be transformed into the $\alpha \beta$ coordinates and the voltage across the virtual impedance needs to be subtracted. Hence, the reference angle and voltage equation can be modified and rewritten $\alpha \beta$ coordinates as

$$
\begin{aligned}
& V_{\alpha-k}^{\mathrm{ref}}=V_{k} \cos \delta_{k}+X_{\mathrm{v}}^{k} I_{\mathrm{g}}^{k} \sin \theta_{\mathrm{g}}^{k} \\
& V_{\beta-k}^{\mathrm{ref}}=V_{k} \sin \delta_{k}-X_{\mathrm{v}}^{k} I_{\mathrm{g}}^{k} \cos \theta_{\mathrm{g}}^{k}
\end{aligned}
$$

where $X_{\mathrm{v}}^{k}=\omega_{\text {ref }} L_{\mathrm{v}}^{k}$ and $i_{\mathrm{g}}^{k}=I_{\mathrm{g}}^{k} \angle \theta_{\mathrm{g}}^{k}$ are respectively the virtual impedance and current passing via the coupling inductance. Next, using the modified droop control technique, the reference for the voltage and phase angle for the LSC of MG- $k$, are

$$
\begin{gathered}
V_{\mathrm{dr}}^{k}=\sqrt{\left(V_{\alpha-k}^{\mathrm{ref}}\right)^{2}+\left(V_{\beta-k}^{\mathrm{ref}}\right)^{2}} \\
\delta_{\mathrm{dr}}^{k}=\tan ^{-1}\left(\frac{V_{\beta-k}^{\mathrm{ref}}}{V_{\alpha-k}^{\mathrm{ref}}}\right)
\end{gathered}
$$

From (15), the instantaneous reference voltage for the LQR switching control block for the LSC of MG- $k$ is

$$
\begin{gathered}
V_{\mathrm{a}-k}^{\mathrm{ref}}=V_{\mathrm{dr}}^{k} \sin \left(\omega_{\text {ref }} t+\delta_{\mathrm{dr}}^{k}\right) \\
V_{\mathrm{b}-k}^{\mathrm{ref}}=V_{\mathrm{dr}}^{k} \sin \left(\omega_{\text {ref }} t+\delta_{\mathrm{dr}}^{k}-120^{\circ}\right) \\
V_{\mathrm{c}-k}^{\mathrm{ref}}=V_{\mathrm{dr}}^{k} \sin \left(\omega_{\text {ref }} t+\delta_{\mathrm{dr}}^{k}-240^{\circ}\right)
\end{gathered}
$$

where $\omega_{\text {ref }}$ is selected based on the fixed frequency of the interconnecting lines (e.g., $50 \mathrm{~Hz}$ ). The virtual impedances that can help to produce power-sharing between MG- $i$ and $j$ can be determined from their droop coefficients via

$$
\frac{m_{\mathrm{MG}-i}}{m_{\mathrm{MG}-j}}=\frac{L_{\mathrm{g}}+L_{\mathrm{v}}^{i}}{L_{\mathrm{g}}+L_{\mathrm{v}}^{j}}
$$

Figure 8 shows the block diagram of the modified angle-voltage droop control technique. It may be noted here that the central controller of an MG determines the amount of power that is going to be shared by each HMG and it is governed by numerous factors, such as the distance among the MGs, the cost of power generation, line loss, willingness to 
participate in power exchange, and so on. Different types of optimization and decisionmaking techniques that determine the optimum power-sharing and estimate the desired droop coefficients are proposed in other studies Hence, using (17), the droop coefficient of $m_{\mathrm{MG}}$ and $n_{\mathrm{MG}}$ is updated.

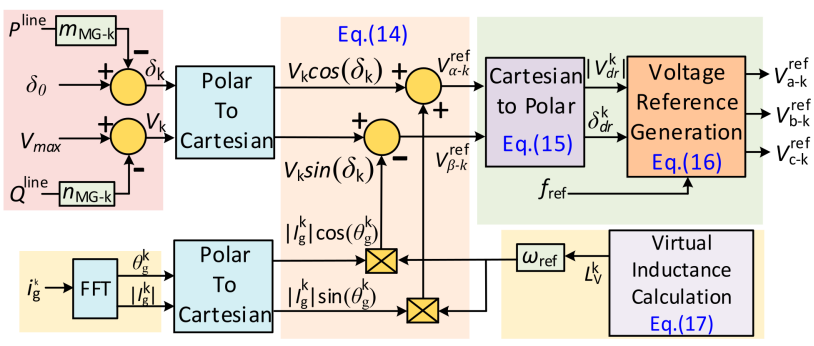

Figure 8. Modified angle-voltage droop control employed for the LSC during HMG operation.

The frequency response plot of the LSCs of two HMGs operating under modified angle droop control, while supporting one PMG, is shown in Figure 9. The plot shows both the angle and the voltage droop response of the LSCs. It may be mentioned here that the power-sharing ratio of the two LSCs operating under droop mode is set to 2:1 in this example. Hence, it can be seen from Figure 9 that the LSC with the larger droop coefficients presents a slightly smaller gain and phase margin compared to the other LSC with smaller droop coefficients.

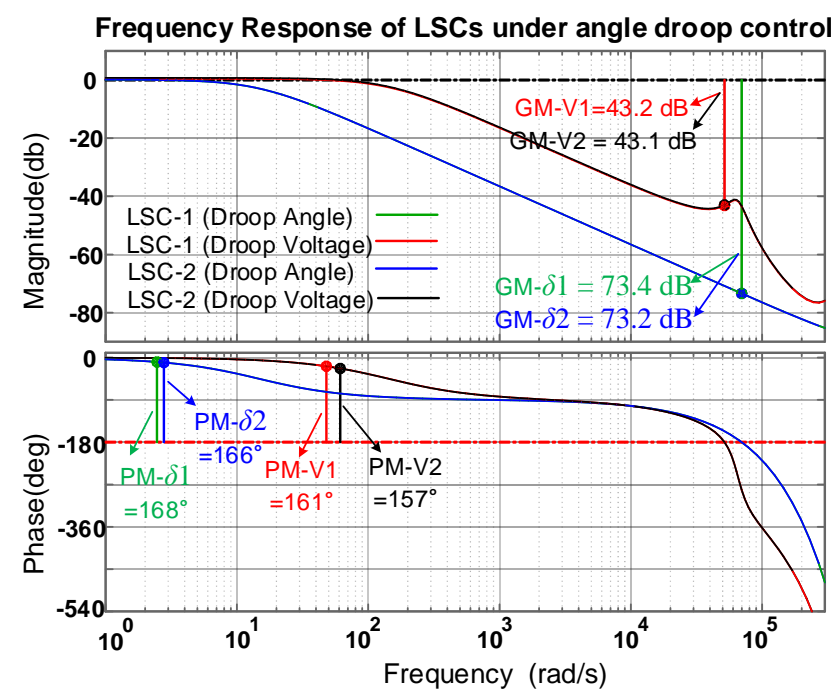

Figure 9. Frequency response plots of LSC operating under modified angle-voltage droop control.

\subsubsection{PMG Operation (PQ Control Mode)}

When an MG becomes a PMG, the frequency control is used. If the PMG is overloaded, then an overload frequency controller (OLFC) defines the amount of power to be absorbed from the neighboring MGs to maintain the frequency of the MG within the desired boundary. Likewise, if the PMG is experiencing excessive generation, the overgeneration frequency controller (OGFC) defines the amount of power to inject into the neighboring MGs. Therefore, the LSC of a PMG functions in constant PQ control mode, as seen in Figure 10. Depending on the frequency deviation, the active power's reference $\left(P_{\text {ref }}\right)$ is calculated while the reactive power's reference $\left(Q_{\text {ref }}\right)$ is presumed as zero. After the alleviation of the overloading or over-generation, the system's state is determined to be normal with the help of another frequency deviation-based controller. Next, the LSC of that MG converts its mode of operation to droop control. 


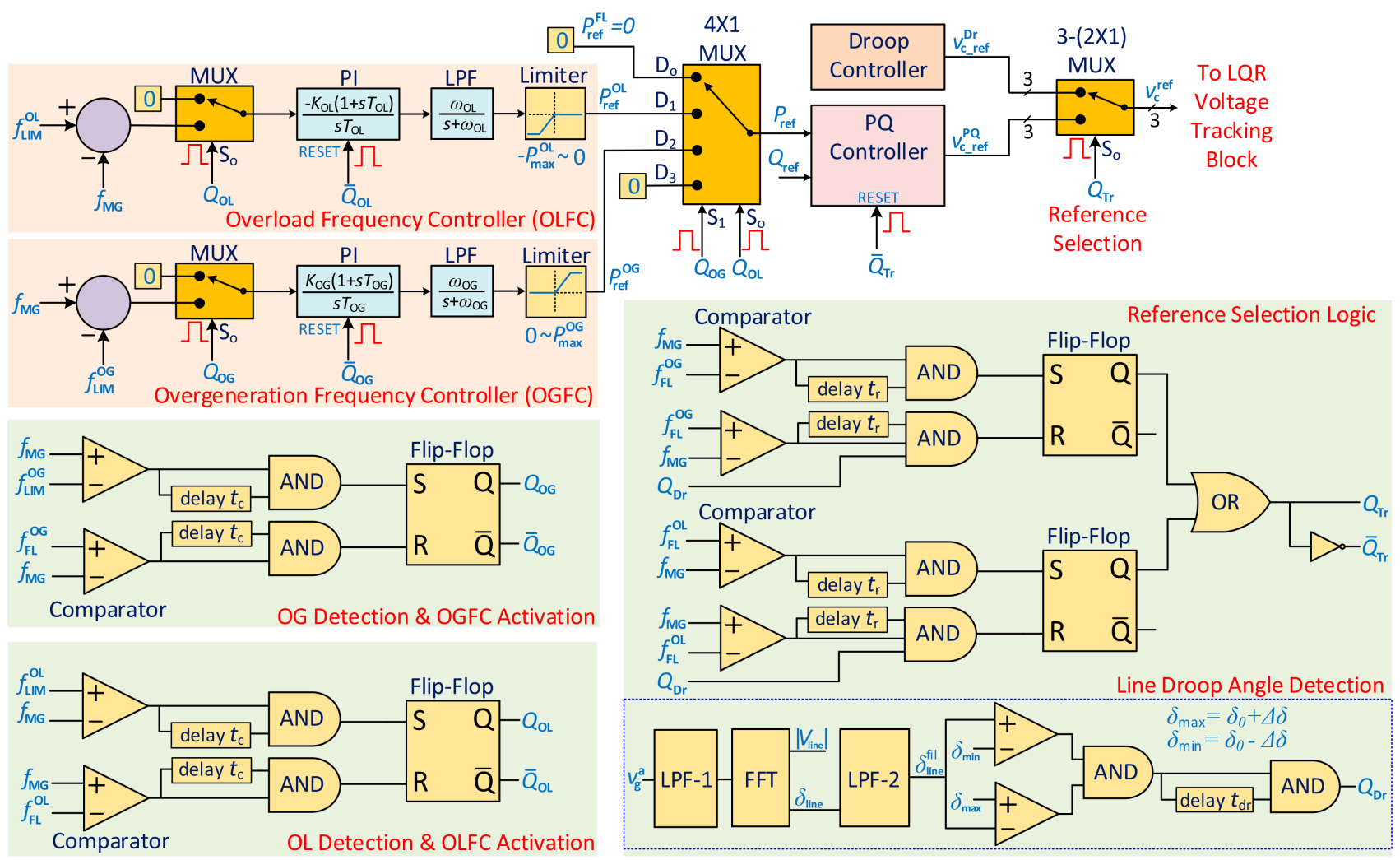

Figure 10. Frequency and reference selection controller of LSC for PMG operation.

Two different PI controllers, along with the required control logic, are employed to define the power references within the frequency controller. At that time, through a $4 \times$ 1 multiplexer, the desired power reference is selected by activating the OLFC or OGFC, respectively, during overloading or over-generation.

A reference selection logic is also essential to transfer between droop control mode (for HMG) and constant PQ control mode (for FMG and PMG) smoothly and without oscillations. Through three $2 \times 1$ multiplexers, this reference selector chooses the threephase reference voltages from the droop control block or the PQ controller block. If the droop block's references are chosen, the PI controllers within the PQ block should also be reset (to prevent an integrator drift and thereby unwanted overshoot upon activation). The switchover from droop to constant PQ mode is straightforward as only the reset signals need to be removed. This is also true when an HMG becomes FMG or PMG. On the other hand, when a PMG/FMG becomes HMG, an additional line angle detection logic is essential. This is because a PMG or FMG should not be permitted to switch back to droop mode before all the remaining MGs are HMG and operating in the same phase angle, $\delta_{0}$. Thus, $\delta_{0}$ is the phase angle of the line voltage when no power flows from/to the MGs through the interconnecting lines (i.e., $P_{\text {line }}=0$ ). Therefore, a line angle detection system, comprising a fast Fourier transform (FFT) block and a window detector, is required, as shown in Figure 10. Hence, the PQ controller of the LSC needs to be modified, as shown in Figure 11, to facilitate the switchover. The overall control block diagram of the frequency controller is shown in Figure 12. 


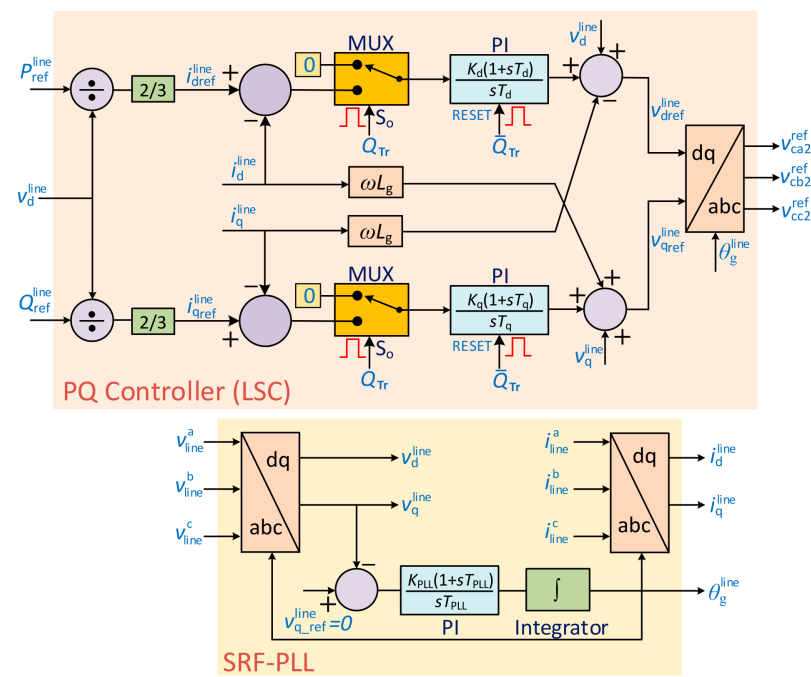

Figure 11. Block diagram of modified PQ controller for LSC operation.

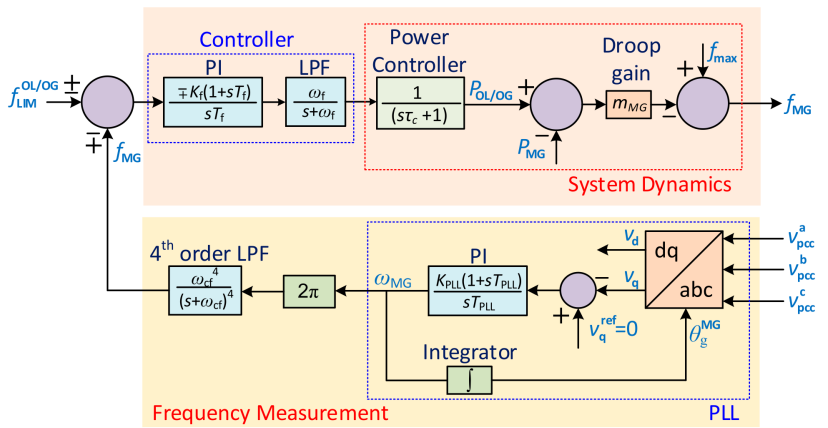

Figure 12. Frequency controller for overload and over-generation prevention.

To design the frequency controller, $P_{\mathrm{MG}}$ and $f_{\max }$ can be considered as a disturbance to the system. The PI controller employed for the PLL is very fast compared to the overall system dynamics and LPF; hence, the PLL block can be assumed to be a unity gain block, and thus, the overall control block diagram of Figure 12 can be represented as in Figure 13. Based on the closed-loop control system of Figure 13, the PI controllers can be designed based on the symmetrical optimum method as, described in [41]. The bode plot of the closed-loop frequency regulation controller is shown in Figure 14.

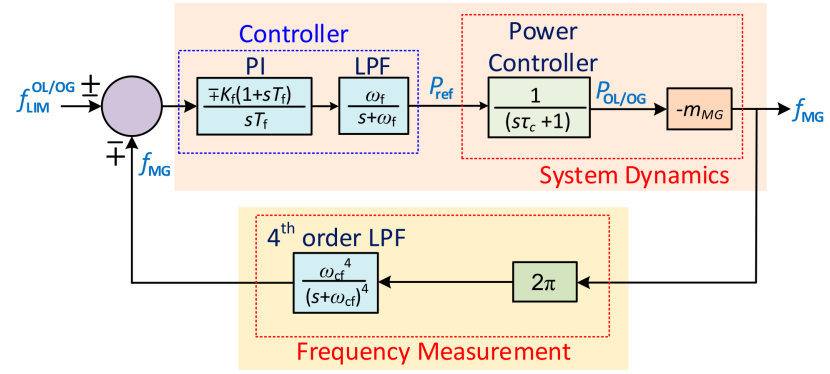

Figure 13. Assumed closed-loop control structure of frequency controller. 


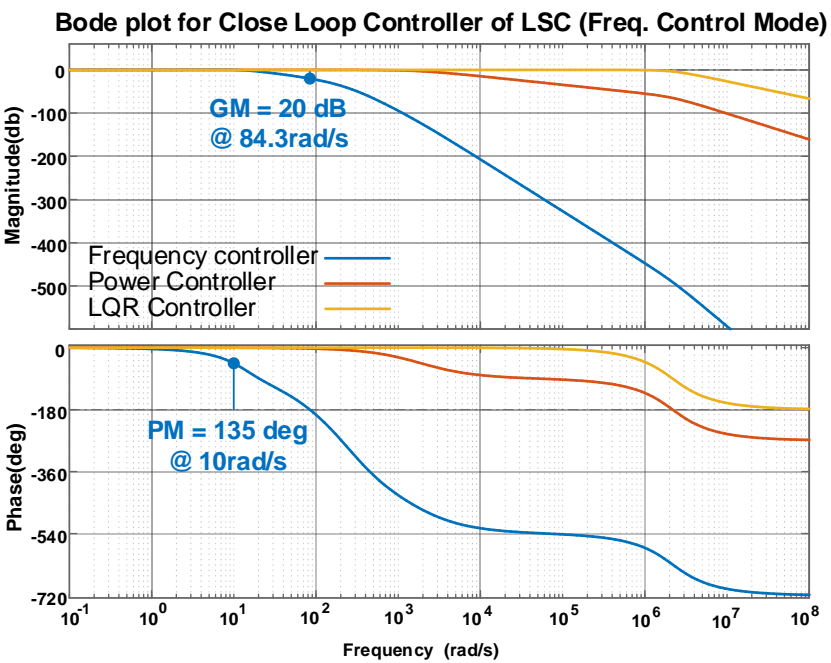

Figure 14. Frequency response plots of LSC operating under frequency control mode.

\section{Performance Evaluation}

Consider a CMG formed by three MGs through a three-phase interconnecting link and back-to-back converters in the system of Figure 1a. This system's performance was evaluated under normal, overloading, and excessive generating conditions. Each MG operates under a voltage and frequency droop while the Appendix A provides the network and controller parameters. The results of the study are presented in Figures 15 and 16 . The results show each MG's frequency, the power exchanged at the output of the LSC of each MG with the interlinking lines. The results also illustrate the voltage of the dc-link, the references for the active powers, and the voltage angles at the output of the LSCs. The figures also illustrate the transfer commands of the LSC controllers.

\subsection{Case Study 1}

In this case study, first, the MG-1 experiences overloading; hence, with the help of the proposed power exchange and control strategy, MG-2 and 3 (the other two HMGs) start supplying the essential demand of MG-1. After a certain period, overloading in MG-1 is complete and all the three MGs operate as HMGs. Later, MG-3 starts experiencing overgeneration, and hence, MG-1 and MG-2 start absorbing the excess power from it to maintain its minimum or baseload power demand. The objective of this case study is to validate the efficacy of the power exchange mechanism, which demonstrates that both overloading or over-generation problems can be addressed effectively, and the injected/absorbed power is shared based on the MG's droop ratio. 


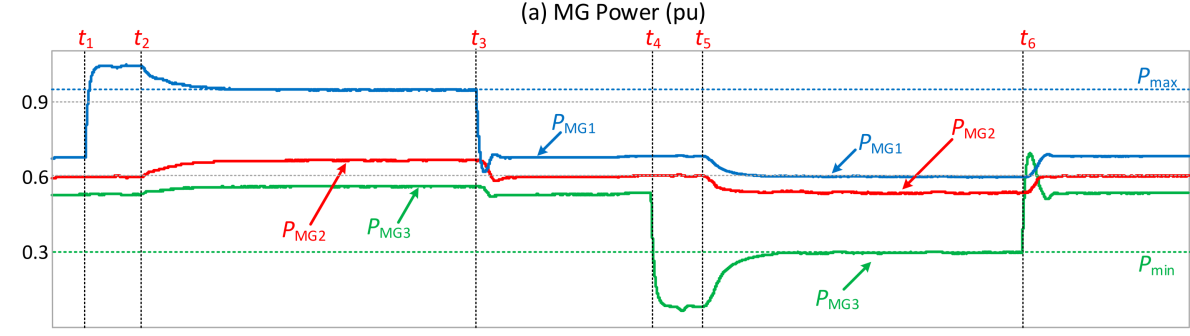

(b) Exchanged Power (pu)

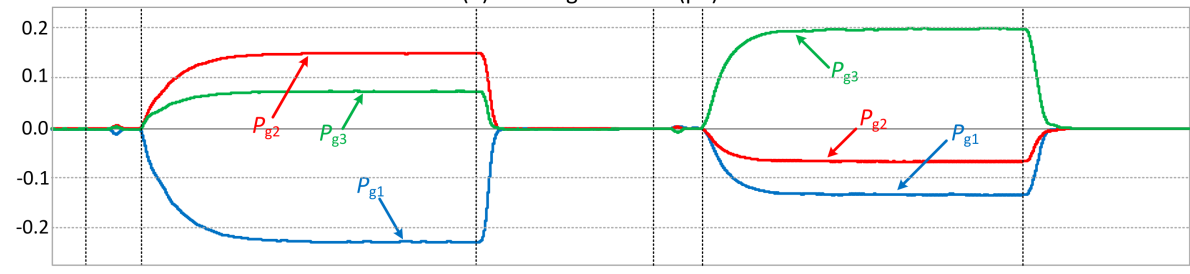

(c) Frequency $(\mathrm{Hz})$

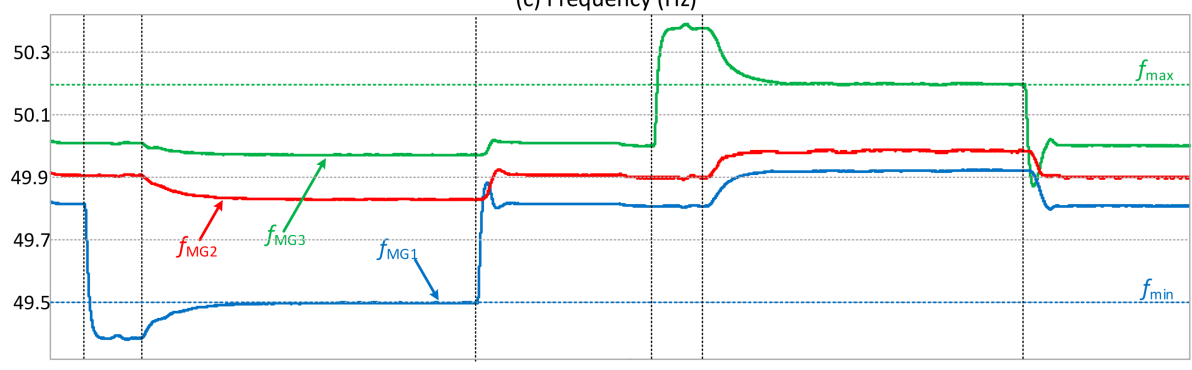

(d) DC link voltage (pu)
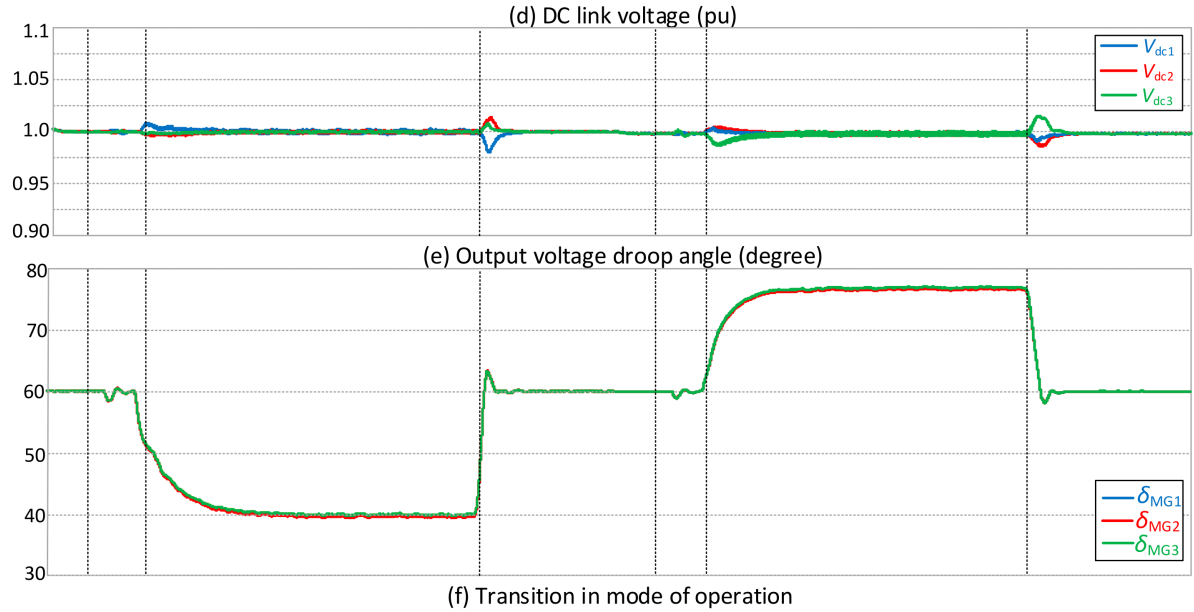

(f) Transition in mode of operation
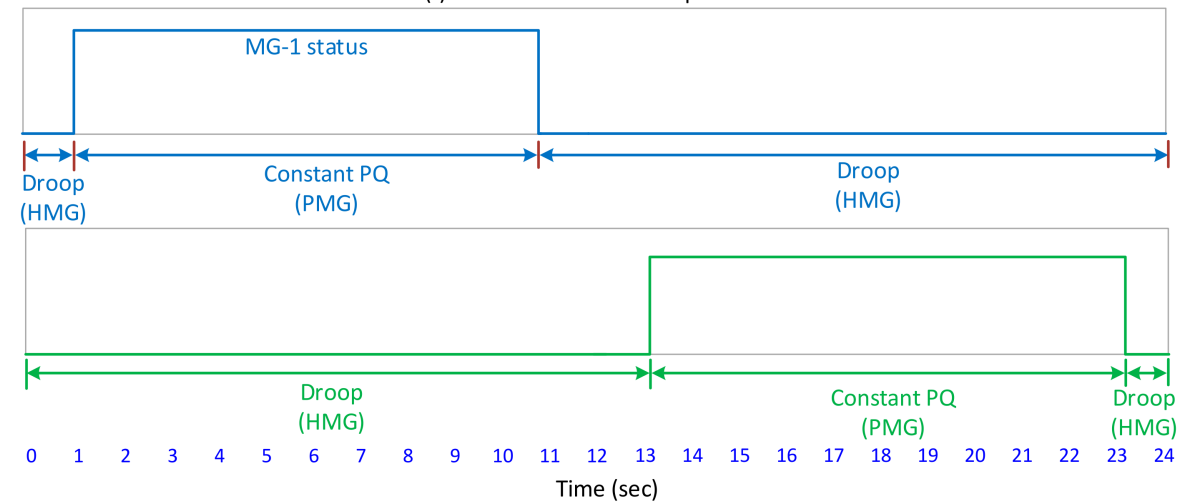

Figure 15. Simulation results of case study 1. 
(a) MG Power (pu)

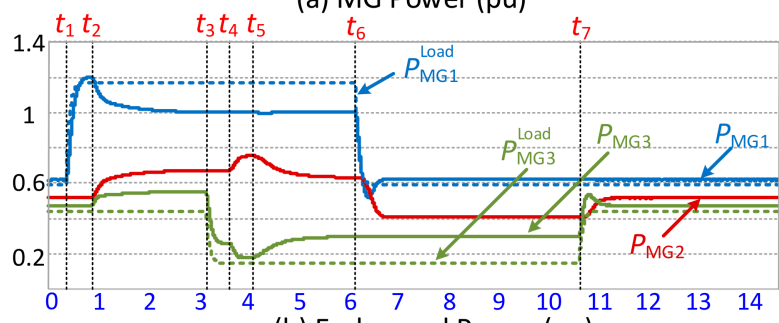

(b) Exchanged Power (pu)
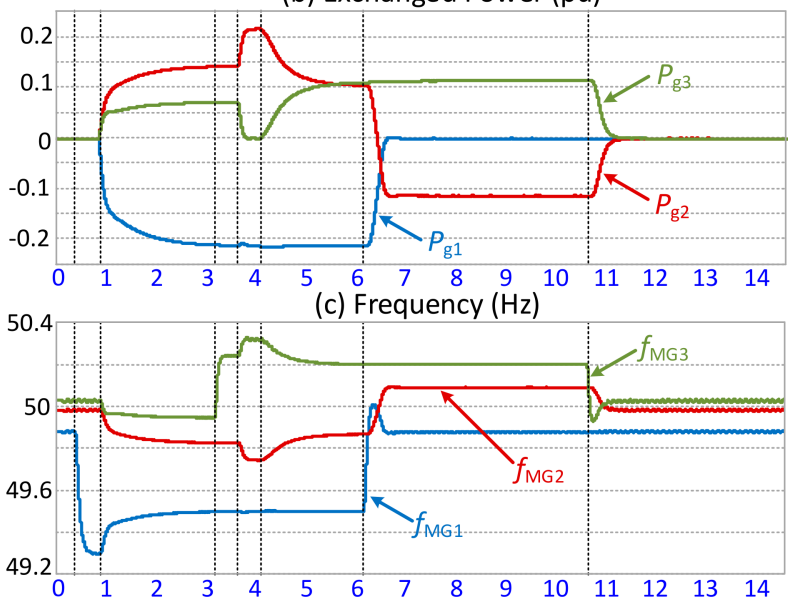

(d) DC link voltage (pu)

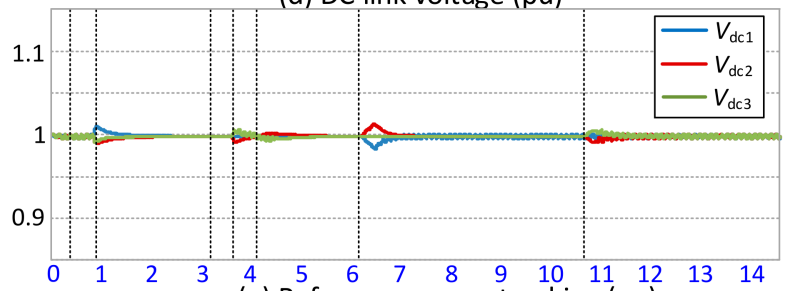

(e) Reference power tracking (pu)
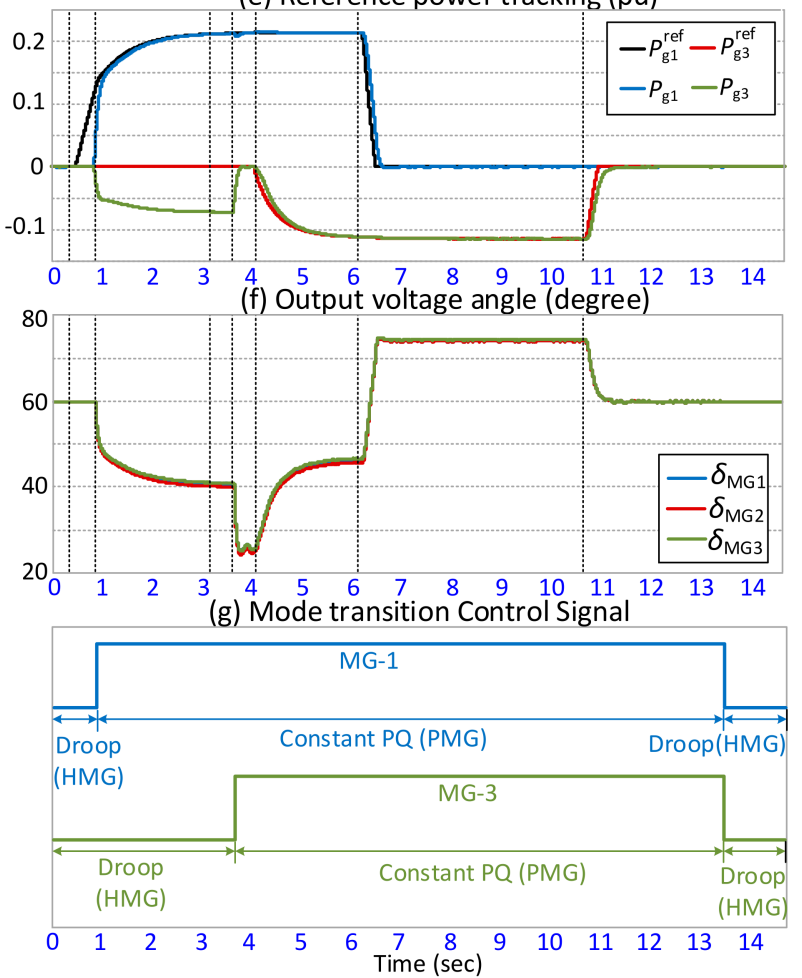

Figure 16. Simulation results of case study-2. 
At first, all the MGs are at steady-state status and operating under the droop control mode with zero power exchange as all the MGs are HMGs. At $t=t_{1}$, as shown in Figure 15a, MG-1 is overloaded by $20 \%$; thus, as shown in Figure 15c, its frequency drops from 49.8 to $49.3 \mathrm{~Hz}$, which is below the acceptable limit of $49.5 \mathrm{~Hz}$. As a result, MG-1 is now a PMG. MG-1's frequency controller recognizes the PMG situation and switches its LSC's mode of operation to constant PQ after a specified time delay (i.e., $0.6 \mathrm{~s})$. Hence, the OLFC becomes active and defines the power level that has to be absorbed to maintain the frequency within the desired boundary. Therefore, at $t=t_{2}, \mathrm{MG}-2$ and MG-3 start supplying active power of 0.155 and $0.076 \mathrm{pu}$, respectively, as shown in Figure 15b. This ratio is defined from the assumed 1:2 droop ratio. The required demand of MG-1 is $0.22 \mathrm{pu}$ and the rest of the supplied power by MG-2 and MG-3 overcomes the losses of the interconnection lines. At $t=t_{3}, \mathrm{MG}-1^{\prime}$ s overloading is alleviated, and its frequency rises to $49.8 \mathrm{~Hz}$ (i.e., above the minimum acceptable threshold). Thus, MG-1 becomes an HMG again, and as can be shown in Figure 15f, its frequency controller changes its operation mode back to droop control. Therefore, MG-2 and MG-3 stop supporting MG-1. At $t=t_{4}$, as shown in Figure 15a, MG-3 experiences 18\% overgeneration, and as seen in Figure 15c, its frequency rises from 49.94 to $50.36 \mathrm{~Hz}$ (above the allowed threshold of $50.2 \mathrm{~Hz}$ ). Therefore, MG-3 is now a PMG. Its frequency controller detects the status and, after a delay of $0.6 \mathrm{~s}$, commands its LSC to switch to constant PQ control mode. Hence, the OGFC becomes active and defines the power level that MG-3 should export to maintain its frequency back within the permissible boundary. Therefore, as can be seen in Figure 15b, at $t=t_{5}, \mathrm{MG}-3$ starts injecting 0.195 pu active power to the interconnecting lines, which is absorbed by MG-1 and MG-2 by 0.121 and $0.062 \mathrm{pu}$, respectively. This ratio is $1: 2$, as required by their assumed droop ratios. At $t=t_{6}$, the overgeneration of MG-3 is eased, and its frequency drops to $49.94 \mathrm{~Hz}$ (i.e., below the level of the maximum permissible threshold of $50.2 \mathrm{~Hz}$ ). Consequently, MG-3 again becomes an HMG and its frequency controller changes its LSC's operation mode to droop control. Therefore, MG-1 and MG-2 stop importing power from MG-3. Table 1 summarizes the events of the MGs and the relevant actions in case study 1.

Table 1. Events applied to MGs in case study1 at different intervals for the overloading scenario.

\begin{tabular}{|c|c|c|c|c|}
\hline \multirow{2}{*}{ Time Instant } & \multicolumn{3}{|c|}{ MG Status } & \multirow{2}{*}{ Action Taken } \\
\hline & MG-1 & MG-2 & MG-3 & \\
\hline$t_{1}$ & OL & HMG & HMG & $\begin{array}{l}\text { Normal operation for MG-2 and MG-3 while MG-1 is } \\
\text { overloaded. }\end{array}$ \\
\hline$t_{2}$ & PMG & HMG & HMG & $\begin{array}{l}\text { MG-1 is overloaded, while MG-2 and MG-3 are supporting it } \\
\text { by supplying the overload power. }\end{array}$ \\
\hline$t_{3}$ & HMG & HMG & HMG & $\begin{array}{l}\text { Over-generation of MG-1 is complete, and all MGs become } \\
\text { HMG. }\end{array}$ \\
\hline$t_{4}$ & HMG & HMG & OG & $\begin{array}{l}\text { Normal operation for MG-1 and MG-2 while MG-3 is } \\
\text { over-generating. }\end{array}$ \\
\hline$t_{5}$ & HMG & HMG & PMG & $\begin{array}{l}\text { MG-3 is over-generating, while MG-1 and MG- } 2 \text { are } \\
\text { supporting it by absorbing the excess power. }\end{array}$ \\
\hline$t_{6}$ & HMG & HMG & HMG & Over-generation of MG-3 is over, and all MGs become HMG. \\
\hline
\end{tabular}

\subsection{Case Study-2}

Now, let us assume that the system is initially in a steady-state condition, and all the MGs are HMG. At $t=t_{1}$, as shown in Figure 16a, MG-1 overloads by 20\%; hence, its frequency drops to $49.3 \mathrm{~Hz}$ (lower than the minimum threshold of $49.5 \mathrm{~Hz}$ ), as shown in Figure 16c. Therefore, the controller changes the operation mode of the LSC of MG-1 to constant PQ control after a predefined delay of $0.6 \mathrm{~s}$. At $t=t_{2}, \mathrm{MG}-2$ and 3 start to inject power to MG-1 to maintain its frequency. The ratio of the power delivered by MG-2: 
MG-3 is 1:2, based on their assumed droop ratios. At $t=t_{3}, \mathrm{MG}-3$ observes an excessive generation following an internal demand drop and, consequently, turns to a PMG after a 0.6 $\mathrm{s}$ delay at $t=t_{4}$. At this time, the controller changes the mode of operation of the LSC of MG-3 to constant PQ control with zero power-sharing as it is not participating in supplying MG-1. In this period, all the excess demand of MG-1 is supplied solely by MG-2. At $t=t_{5}$, MG-3 changes its mode of operation to constant PQ and supplies MG-1 with an excess power of $0.12 \mathrm{pu}$. At $t=t_{6}, \mathrm{MG}-1^{\prime}$ s overloading is stopped after its internal demand reduces by $20 \%$. Hence, MG-1 becomes an HMG again. However, it is not permitted to switch back to droop mode as it cannot be synchronized with the interconnecting link. Therefore, it continues operating in PQ mode with zero output power reference. In this period, onlyMG-2 absorbs the excess power of MG-3. At $t=t_{7}$, all the MGs become HMGs, and after a delay of 2 s (imposed by the mode transition controller), both MG-1 and 3 change back to droop mode and continue operating under their normal conditions. Table 2 summarizes the events of the MGs and the relevant actions of case study 2.

Table 2. Overloading and over-generating events applied to MGs in case study 2 at different intervals.

\begin{tabular}{ccccc}
\hline Time Instant & MG-1 & $\begin{array}{c}\text { MG Status } \\
\text { MG-2 }\end{array}$ & MG-3 & Action Taken \\
\hline$t_{1}$ & OL & HMG & HMG & $\begin{array}{c}\text { Normal operation for MG-2 and MG-3 while MG-1 is } \\
\text { overloaded. }\end{array}$ \\
\hline$t_{2}$ & PMG & HMG & HMG & MG-1 becomes overloaded, so MG-2 and 3 support it. \\
\hline$t_{3}$ & PMG & HMG & OG & MG-3 is over-generating. \\
\hline$t_{4}$ & PMG & HMG & FMG & MG-3 changes its operation mode from droop to PQ but shares \\
zero power. MG-2 is supporting MG-1.
\end{tabular}

\section{Stability Analysis}

To evaluate the robustness of a CMG operating according to the proposal, a stability analysis of the three-phase CMG topology was carried out. The stability analysis was performed by varying numerous key design factors (i.e., the droop coefficients, the impedance of the interconnecting line, and the demand level of the PMG). The small-signal stability results are an eigenvalue evaluation, based on the method proposed by the authors in [46,47], extended and reutilized in this work to consider the stability of CMGs. The eigenvalue plots obtained from the stability analysis are shown in Figures 17-19. 


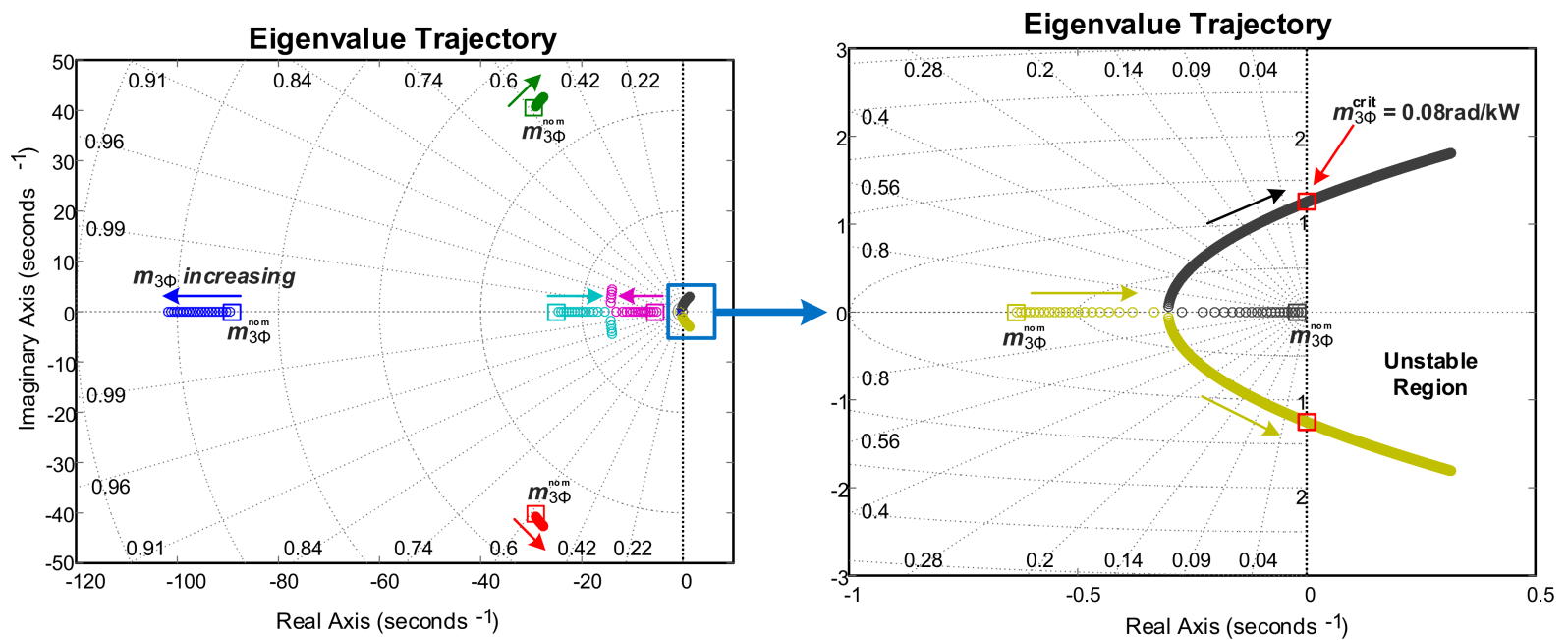

(a)
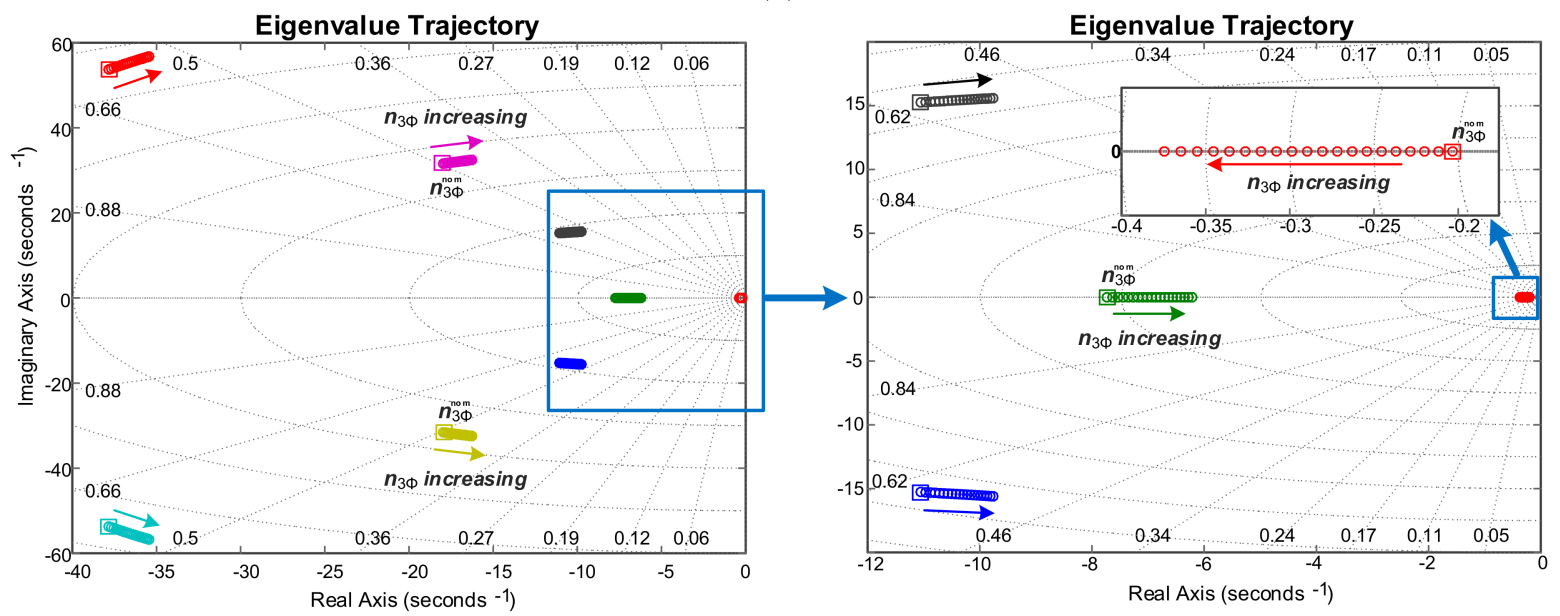

(b)

Figure 17. Eigenvalue trajectory for variation of droop coefficients (a) $m_{\mathrm{MG}}$ (b) $n_{\mathrm{MG}}$.

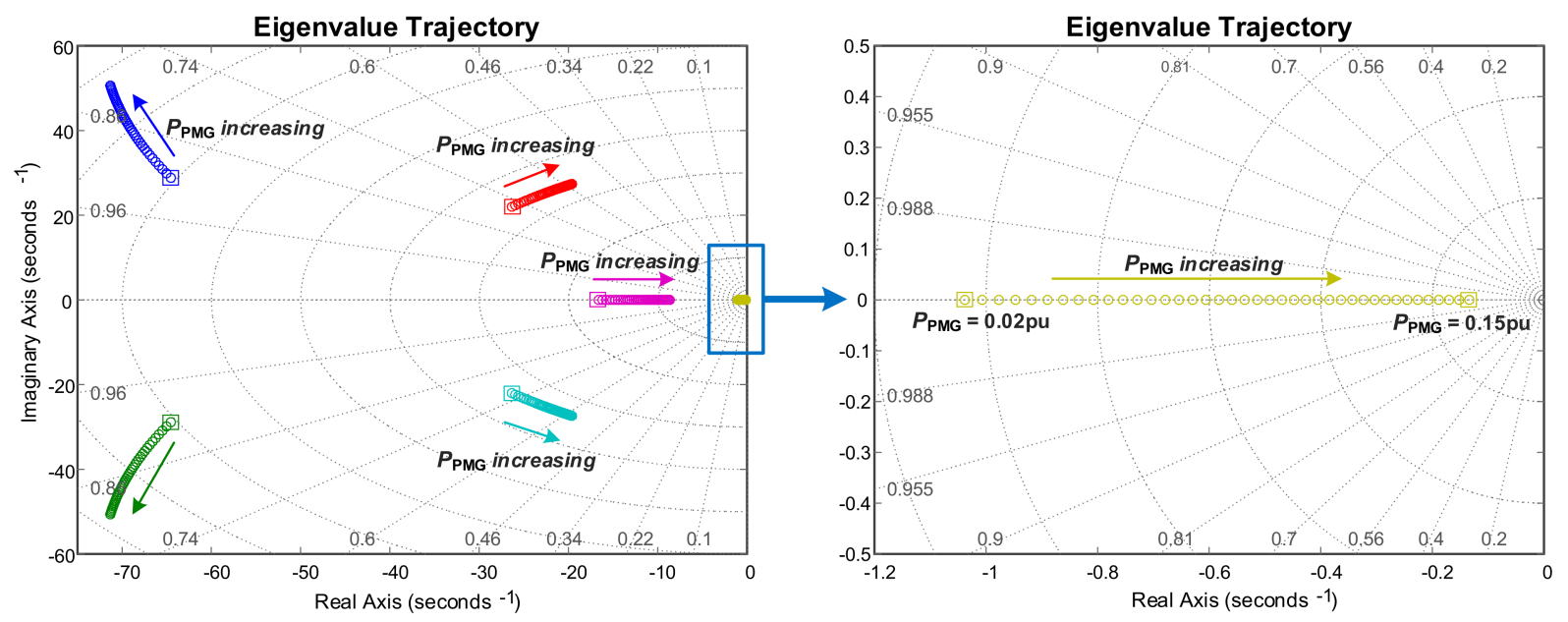

Figure 18. Eigenvalue trajectory for PMG power exchange. 


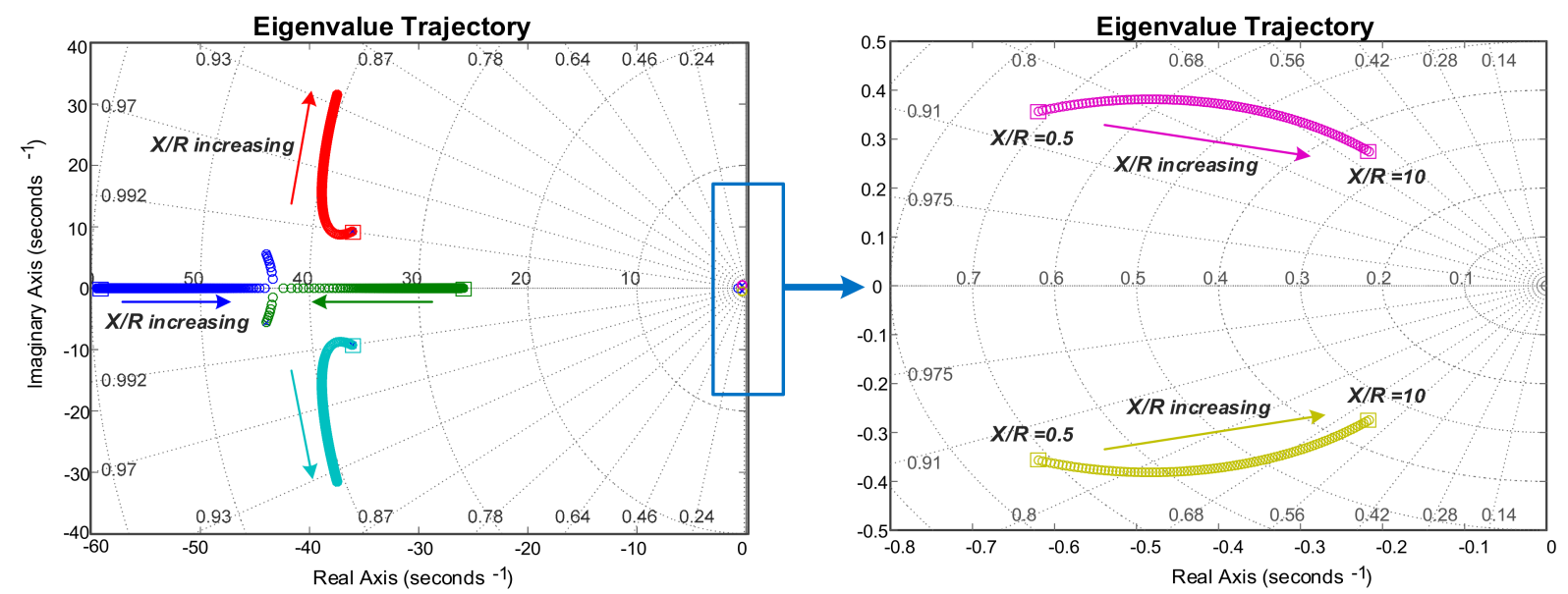

Figure 19. Eigenvalue trajectory for line impedance.

\subsection{Droop Coefficients}

Let us consider that the active power droop coefficient of $m_{\mathrm{MG}}$ is varied around its nominal value of $0.002 \mathrm{rad} / \mathrm{kW}$. The critical value of $m_{\mathrm{MG}}$ is obtained as $m_{3 \varnothing}^{\text {crit }}=0.08 \mathrm{rad} / \mathrm{kW}$, which can be seen in Figure 17a. A further increase in $m_{\mathrm{MG}}$ causes instability in the CMG. This is also verified by time-domain simulation in PSIM, and the critical value is obtained as $m_{3 \varnothing}^{\text {crit }}=0.076 \mathrm{rad} / \mathrm{kW}$, which is almost equal to the values obtained from the MATLAB simulation. On the other hand, as shown in Figure $17 \mathrm{~b}$, the variation of $n_{\mathrm{MG}}$ does not significantly affect the CMG stability as the reactive power flowing through the CMG network is very small. The value of $n_{\mathrm{MG}}$ was varied from its nominal value of $0.004 \mathrm{rad} / \mathrm{kVAR}$ up to $0.4 \mathrm{rad} / \mathrm{kVAR}$ (i.e., 100 times its nominal value) to obtain the eigenvalue trajectory plots. Compared with stability analysis presented in [24], where the CMG topology is formed using a single-phase link, the proposed three-phase link exhibits more system damping and better gain and phase margin, as can be seen from their location of dominant eigenvalues.

\subsection{PMG Power}

The amount of power exchanged between the PMG and the interconnecting line also affects the CMG's dynamic response. To observe this, the PMG power was varied from $0.02 \mathrm{pu}$ to $0.15 \mathrm{pu}$; the corresponding eigenvalues are plotted. This is shown in Figure 18. As the PMG power increases, the system damping increases, and the response becomes slightly sluggish. In other words, the CMG network performs better when a larger amount of power is exchanged among the microgrids forming the CMG. It can be observed from Figure 18 that the dominant eigenvalue moves towards the right as the PMG power increases, thereby making the system response sluggish; however, this variation in the PMG power level does not lead to system instability, as can be seen from the eigenvalue plot. Nevertheless, the maximum power that can be exchanged in the CMG network depends on the line impedance for a given voltage level.

\subsection{Interconnecting Line Impedance}

Let us evaluate the impact of the interconnecting line's impedance (i.e., the line reactance to resistance ratio, termed $X / R$ ) on the CMG's stability. In this study, the line inductance is increased from 0.16 to $3.2 \mathrm{mH}$ while the line's resistance is $0.1 \Omega$ and constant. The evaluated eigenvalues are shown in Figure 19. It can be observed that an increase in the $X / R$ ratio, i.e., an increase in the line inductance, reduces system damping and makes the system response oscillatory as the complex conjugate pair of eigenvalues moves towards the right (see Figure 19). A higher $X / R$ ratio introduces a larger voltage drop in the line and restricts the maximum power transferring limit; however, better power-sharing accuracy is observed for larger $X / R$ ratios. 


\subsection{Discussion of Results}

The stability assessment demonstrates that, amongst all the studied factors, the active power droop coefficient, $m_{\mathrm{MG}}$, exhibits the key influence over a CMG's stability and can lead to instability if not properly designed/selected. On the other hand, the CMG stability is not affected strongly by the reactive power droop coefficient, $n_{\mathrm{MG}}$, as the reactive power flowing through the interconnecting lines is marginal. The study also demonstrates that even though the amount of power exchanged by the PMG affects the system's response, it does not lead to system instability. However, the maximum amount of this power is affected by the impedance of the interconnecting line. The larger the $X / R$ ratio of the interconnecting line, the larger the voltage drop in the line and, hence, the lower the maximum amount of the power exchange limit; however, the larger the $X / R$ ratio, the better the power-sharing accuracy.

\section{Sensitivity Analysis}

The sensitivity of the power exchange link and the employed control strategy for the CMG link was analyzed against the design and operational factors. This study tries to determine the relationship between the variation of the interconnecting line impedance (i.e., the distance of the MGs from each other) and the amount of power delivered or absorbed by a PMG with the power exchange link's performance. The line loss, the amount of power delivered/absorbed from the HMGs to the PMG, the LSC's voltage and droop angle, the HMG's frequency, the dc-link voltage, and, finally, the error in power-sharing, were evaluated in the sensitivity analysis. The sensitivity studies were performed by re-running the time-domain dynamic studies for various parameters and then plotting the change in certain outputs versus those variations. The obtained results are shown in Figures 20-22.

(a)

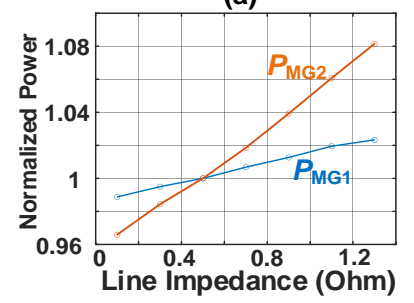

(b)

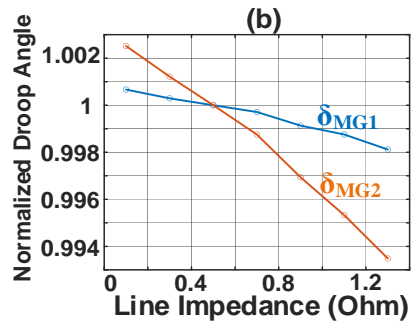

(c)

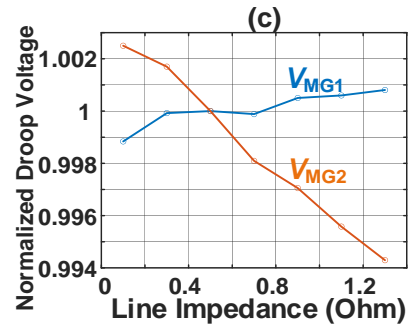

(d)

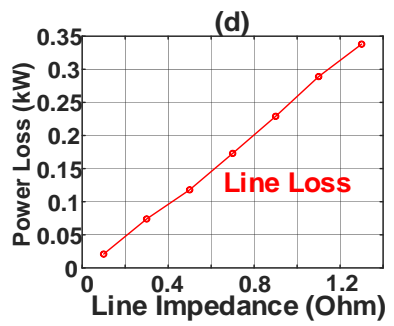

Figure 20. Sensitivity analysis with variation of interconnecting line impedance (a) power (b) droop angle (c) droop voltage (d) line loss.

\subsection{Line Impedance Variation}

This study is focused on the CMG topology for a scenario where two HMGs are supporting one PMG when sharing the power at a ratio of 2:1. The results show that the power-sharing amongst the HMGs based on their droop ratios is influenced to some extent as the interconnecting line's impedance or the distance amongst the MGs is increased. The error in power-sharing stays within the limit due to the employed modified angle droop control technique using virtual inductance, which minimizes the error margin. It can be noted here that the conventional angle droop technique is highly sensitive to the magnitude of the line impedances, and for the technique to be accurate and applicable, the line reactance should be several times larger than the resistance, which may not always be feasible for practical CMG networks. Moreover, a larger value of droop coefficients drives the system towards instability. To guarantee adequate stability, droop coefficients are selected to be small while leading to the desired power-sharing amongst the MGs based on their droop coefficients. Hence, to ensure the desired power-sharing among the HMGs, the modified angle droop method is employed. One of the main objectives of the sensitivity analysis is to demonstrate the ability to share power among the HMGs operating under the modified angle droop while line impedances are varied, and the ratio of the line resistance to the reactance is larger than unity. The variation in the HMG's shared power through the 
ac link, droop angles, voltages, and the line losses as the impedance varies, are shown in Figure 20a-d. The graphs are plotted considering the situation described in case study 1. The line impedance used in the simulation for the case studies is used as a reference, and all the parameters are normalized based on this value. It can be observed from Figure 20a-d that, as the line impedance is increased, the loss and delivered power by individual MGs increase; however, the line's droop angle and voltages start to drop to cater for the extra line related power loss. These variations are almost linear and as expected, except for the voltage values.

(a)

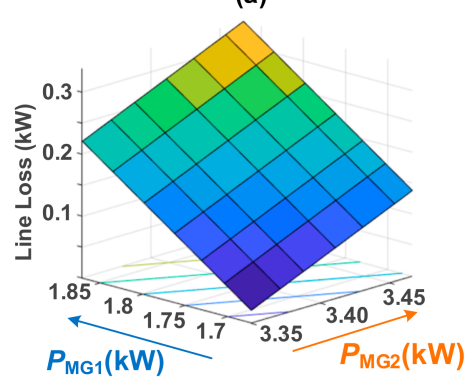

(d)

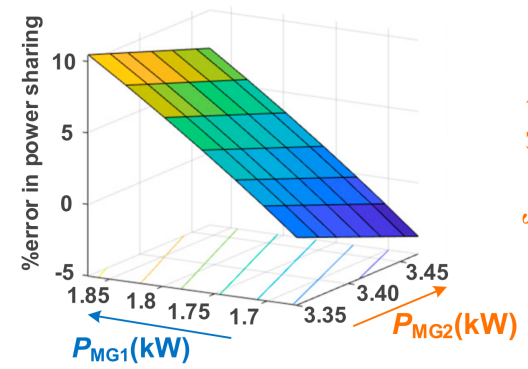

(b)

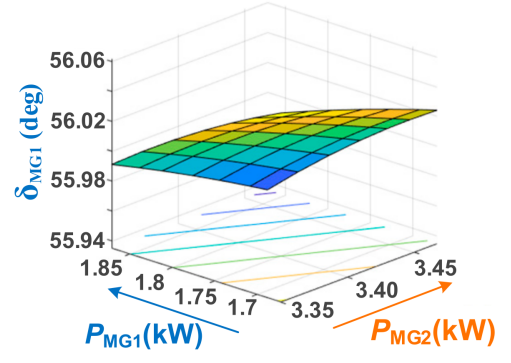

(e)

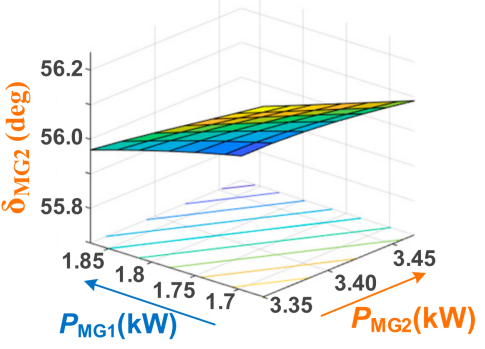

(c)

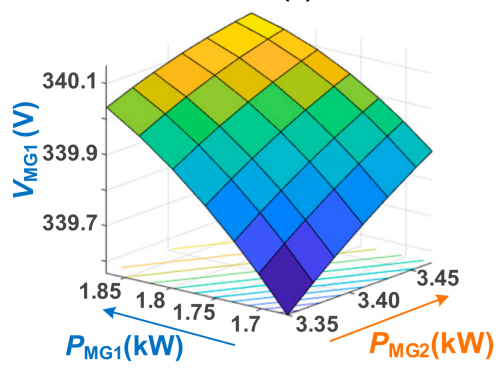

(f)

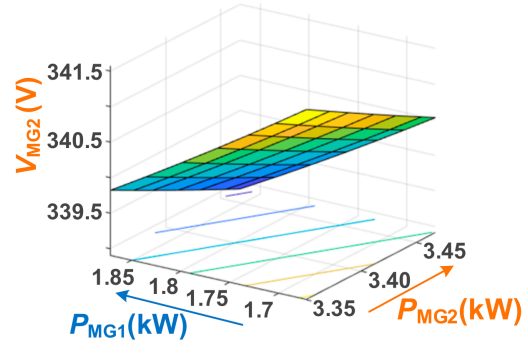

Figure 21. Sensitivity analysis with variation of power from HMGs due to increase in line resistance: (a) line loss (b) droop angle MG-1 (c) droop voltage MG-1 (d) error in power-sharing (e) droop angle MG-2 (f) droop voltage MG-2.
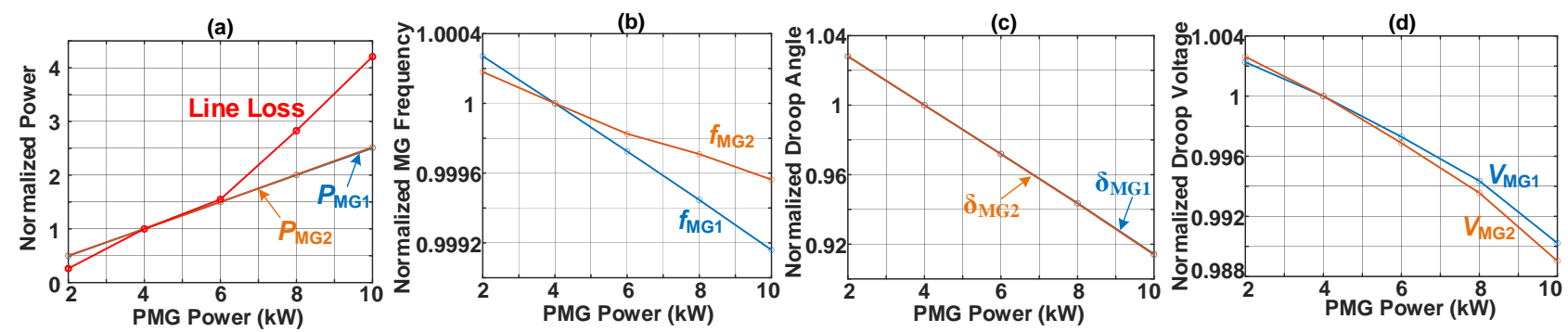

Figure 22. Sensitivity analysis with variation of PMG power demand: (a) line loss and power (b) MG frequency (c) line droop angle (d) line droop voltage.

Figure 21a and Figure 21d, respectively, show the surface plot of the line loss and the percentage of error in the power-sharing as the delivered power by two HMGs change because of an increase in the line's impedance. Figures $21 \mathrm{~b}$ and 21c show the line droop angle and droop voltage of each HMG. The surface graphs of the droop angles of both the HMG's tie lines are similar; nevertheless, the droop voltages demonstrate a different pattern. This variation can also be observed in Figure 20c. As the impedance of the tie-lines is increased, the property of sharing of desired power as per the droop coefficients starts to deviate slightly and produce an error. This is because of the fact that, as the impedances of the lines become larger, the characteristic of power-sharing being reciprocal to the droop coefficients ratio is violated. However, in this study, as the modified angle droop (i.e., the use of virtual impedance to ensure the desired power-sharing) is implemented, the 
error stays within an acceptable range, therefore the droop control technique is effective at producing the desired power-sharing amongst the MGs. As can be seen from Figure 21d, a variation in impedance from 0.1 to $1.3 \Omega$ causes an error of -4 to $+10 \%$, which is within the acceptable range.

\subsection{PMG Power Variation}

The previous analysis was repeated by modifying the PMG's power demand in the CMG network. Figure 22a-d shows the line loss, delivered HMG power, respective HMG's frequency, droop angle, and voltage as the power absorbed by PMG varied from 2 to $10 \mathrm{~kW}$. The plots are normalized based on a value of $4 \mathrm{~kW}$. Figure 12a,c show that power-sharing between two HMGs remains constant regardless of the PMG's power demand and the proposed power-sharing approach is insensitive to the PMG's power demand.

\subsection{Number of Interconnected MG Variation}

The third and final sensitivity analysis was conducted to determine the relative stability margin of the three-phase power exchange network by varying the number of interconnected MGs to form the CMG. The two outer control loops (i.e., power and frequency) of the LSC were examined in this analysis. The frequency responses of the power and frequency control loop with varying numbers of MGs are shown in Figure 23a and Figure 23b, respectively. It can be observed from this analysis that the number of MGs participating in forming the CMG power exchange network affects the dynamic response of the overall system and thus its gain and phase margin. Even though the effect on gain and phase margin is not too significant, coupling a large number of MGs to form the CMG may result in a poor dynamic response or, in some cases, may even make the network unstable. As shown in Figure 23a, the closed-loop phase margin of the power control loop reduces as the number of MGs in the CMG network increases. However, for the frequency loop, the phase margin does not reduce, but the crossover frequency shifts towards the left, resulting in slower dynamic response, as can be seen in Figure 23b. Overall, this study reveals that if a large number of MGs are coupled together to form the CMG, the controllers need to be returned and redesigned in order to achieve the necessary gain and phase margin of the system.

\subsection{Discussion of Results}

The sensitivity assessment demonstrates that the increase in the distance of the MGs from each other or the impedance of the interlinking line increases the line's power loss and thus the power delivered by the HMGs; therefore, the voltage angle at the LSC of the HMGs starts to drop almost linearly. At the same time, the property of sharing of desired power as per the droop coefficients starts to deviate slightly. The studies also show that the proposed power-sharing approach is robust against the variation in the PMG's power demand exchange level. 


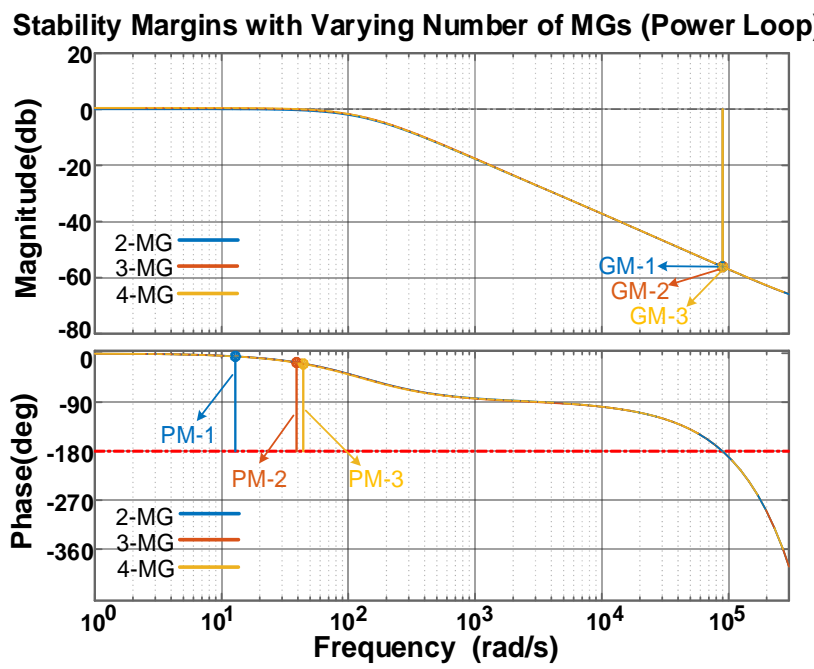

(a)

Stability Margins with Varying Number of MGs (Freq. Loop)

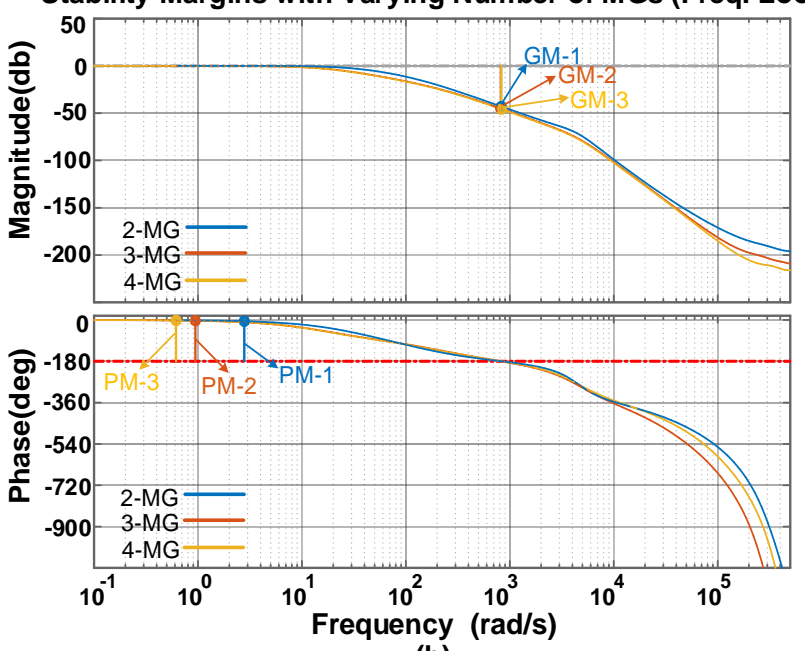

(b)

Figure 23. Sensitivity analysis by varying number of coupled MGs: (a) power control loop (b) frequency control loop.

\section{Conclusions}

This paper focused on the topic of back-to-back power electronic converter-based coupled MGs through a three-phase ac interconnecting link. A decentralized control technique was proposed for the converters to produce proper power exchange from HMGs to PMGs during a temporary power shortfall or excess generation in the MGs. The proposal includes a strategy with which to obtain a preferred power-sharing ratio amongst multiple HMGs and several control techniques to detect the MG status, the power exchange amount, and the changeover between the various operation modes, and is only based on local measurements. The successful performance of the proposed power management, exchange, and control strategy were evaluated through simulation studies, which verified that MGs can retain nominal operating conditions following a power shortfall or excess. This solution can be successfully employed instead of load-shedding or renewables curtailment. The stability assessment demonstrated that, amongst all the studied factors, the active power droop coefficient exhibits the key influence over a CMG's stability. The sensitivity assessment demonstrated a robust performance against key design factors, including the number of MGs within the CMG, the distance of the MGs from each other, the impedance of the interlinking line, and the PMG's power exchange limit. 
Author Contributions: Conceptualization, S.M.F., and F.S.; methodology, S.M.F. and F.S.; software, S.M.F.; validation, S.M.F., F.S., and G.S.; writing—original draft preparation, S.M.F.; writing—review and editing, F.S., and G.S.; supervision, F.S. and G.S.; funding acquisition, F.S. and G.S.; All authors have read and agreed to the published version of the manuscript.

Funding: This research received no external funding.

Institutional Review Board Statement: Not applicable.

Informed Consent Statement: Not applicable.

Data Availability Statement: Not applicable.

Conflicts of Interest: The authors declare no conflict of interest.

$\begin{array}{ll}\text { Nomenclature } \\ \text { CMG } & \text { Coupled Microgrid } \\ \text { DER } & \text { Distributed energy resource } \\ \text { FFT } & \text { Fast Fourier Transform } \\ \text { FMG } & \text { Floating Microgrid } \\ \text { HMG } & \text { Healthy Microgrid } \\ \text { LPF } & \text { Low pass filter } \\ \text { LQR } & \text { Linear Quadratic Equation } \\ \text { LSC } & \text { Line Side Converter } \\ \text { MG } & \text { Microgrid } \\ \text { MSC } & \text { Microgrid Side Converter } \\ \text { OG } & \text { Over-generation } \\ \text { OGFC } & \text { Over-generation Frequency Controller } \\ \text { OL } & \text { Overload } \\ \text { OLFC } & \text { Overload Frequency Controller } \\ \text { PMG } & \text { Problem Microgrid } \\ \text { PCC } & \text { Point of Common Coupling } \\ \text { PI } & \text { Proportional-integral } \\ \text { PLL } & \text { Phase-Locked Loop } \\ \text { VSC } & \text { Voltage source converter }\end{array}$

\section{Appendix A} Table A1.

The network and controller parameters used in the simulation studies are given in

Table A1. Technical data of network under consideration.

\begin{tabular}{l|l}
\hline Network & $V_{\text {rated }}=415 \mathrm{~V}, f_{\text {nom }}=50 \mathrm{~Hz}, f_{\min }=49.8 \mathrm{~Hz}, P_{\max }=70 \mathrm{~kW}, V_{\mathrm{dc}}=1.5 \mathrm{kV}, Z_{\mathrm{MG}}=$ \\
& $0.1+j 0.5 \Omega, Z_{\text {line }}=0.1+j 0.08 \Omega$ \\
\hline DER droop & $m=0.01 \mathrm{~Hz} / \mathrm{kW}, n=0.1 \mathrm{~V} / \mathrm{kVAR}$ \\
\hline Angle droop & $m_{\mathrm{d}}=0.002 \mathrm{rad} / \mathrm{kW}, n_{\mathrm{d}}=0.004 \mathrm{~V} / \mathrm{kVAR}$ \\
\hline Converter and filters & $R_{\mathrm{f}}=0.1 \Omega, L_{\mathrm{f}}=2 \mathrm{mH}, R_{\mathrm{g}}(\mathrm{MSC})=0.04 \Omega, L_{\mathrm{g}}(\mathrm{MSC})=1.36 \mathrm{mH}, R_{\mathrm{g}}(\mathrm{LSC})=0.12 \Omega$, \\
& $L_{\mathrm{g}}(\mathrm{LSC})=10 \mathrm{mH}, C_{\mathrm{f}}=25 \mu \mathrm{F}, C_{\mathrm{dc}}=4700 \mu \mathrm{F}$ \\
\hline LQR gains & $k_{1}=58.63, k_{2}=97.18, k_{3}=1.2, \omega_{c}=6283.2 \mathrm{rad} / \mathrm{s}$ \\
\hline PI-PQ controller for MSCs & Proportional gain, $K_{\mathrm{P}}=0.628$, Time Constant, $T_{\mathrm{I}}=0.034 \mathrm{~s}$, bandwidth, $f_{\mathrm{BW}}=73.5 \mathrm{~Hz}$ \\
\hline PI-PQ controller for LSCs & Proportional gain, $K_{\mathrm{P}}=0.628$, Time Constant, $T_{\mathrm{I}}=0.0834 \mathrm{~s}$, bandwidth, $f_{\mathrm{BW}}=10 \mathrm{~Hz}$ \\
\hline Frequency controller & $K_{\mathrm{OL}}=15 \mathrm{k}, T_{\mathrm{OL}}=0.025 \mathrm{~s}, \omega_{\mathrm{OL}}=314 \mathrm{rad} / \mathrm{s}, K_{\mathrm{OG}}=20 \mathrm{k}, T_{\mathrm{OG}}=$ \\
\hline DC link voltage controller & $0.05 \mathrm{~s}, \omega_{\mathrm{OG}}=37.7 \mathrm{krad} / \mathrm{s}, K_{\mathrm{PLL}}=5, T_{\mathrm{PLL}}=0.02 \mathrm{~s}$ \\
\hline & $K_{\mathrm{dc}}=222, \omega_{\mathrm{z}}=2.2 \mathrm{rad} / \mathrm{s}, \omega_{\mathrm{p}}=1000 \mathrm{rad} / \mathrm{s}, \tau_{\mathrm{dc}}=392.2 \mathrm{~ms}, P_{\mathrm{so}}=100 \mathrm{~kW}, V_{\mathrm{d}}=340 \mathrm{~V}$ \\
\hline
\end{tabular}




\section{References}

1. Lasseter, R.H. Microgrids. In Proceedings of the IEEE Power Engineering Society Winter Meeting. Conference, New York, NY, USA, 27-31 January 2002; Volume 1, pp. 305-308.

2. Lasseter, R.H.; Piagi, P. Microgrid: A conceptual solution. In Proceedings of the IEEE Power Electronics Specialists Conference, Aachen, Germany, 20-25 June 2004; Volume 6, pp. 4285-4291.

3. Lasseter, R.H. Smart Distribution: Coupled Microgrids. Proc. IEEE 2011, 99, 1074-1082. [CrossRef]

4. Yoldaş, Y.; Önen, A.; Muyeen, S.; Vasilakos, A.V.; Alan, İ. Enhancing smart grid with microgrids: Challenges and opportunities. Renew. Sustain. Energy Rev. 2017, 72, 205-214. [CrossRef]

5. De Matos, J.G.; e Silva, F.S.; Ribeiro, L.A.D.S. Power control in ac isolated microgrids with renewable energy sources and energy storage systems. IEEE Trans. Ind. Electron. 2015, 62, 3490-3498.

6. Che, L.; Shahidehpour, M.; AlAbdulwahab, A.; Al-Turki, Y. Hierarchical Coordination of a Community Microgrid With AC and DC Microgrids. IEEE Trans. Smart Grid 2015, 6, 3042-3051. [CrossRef]

7. Liu, G.; Ollis, T.B.; Xiao, B.; Zhang, X.; Tomsovic, K. Networked Microgrids for Improving Economics and Resiliency. In Proceedings of the 2018 IEEE Power \& Energy Society General Meeting (PESGM), Portland, OR, USA, 5-10 August 2018; pp. 1-5. [CrossRef]

8. Abu-Elzait, S.; Parkin, R. Economic and Environmental Advantages of Renewable-based Microgrids over Conventional Microgrids. In Proceedings of the 2019 IEEE Green Technologies Conference(GreenTech), Lafayette, LA, USA, 3-6 April 2019; pp. $1-4$.

9. Arefifar, S.A.; Mohamed, Y.A.R.I. DG mix, reactive sources and energy storage units for optimizing microgrid reliability and supply security. IEEE Trans. Smart Grid 2014, 5, 1835-1844.

10. Che, L.; Zhang, X.; Shahidehpour, M.; AlAbdulwahab, A.; Abusorrah, A. Optimal Interconnection Planning of Community Microgrids With Renewable Energy Sources. IEEE Trans. Smart Grid 2017, 8, 1054-1063. [CrossRef]

11. Zia, M.F.; Elbouchikhi, E.; Benbouzid, M. Microgrids energy management systems: A critical review on methods, solutions, and prospects. Appl. Energy 2018, 222, 1033-1055. [CrossRef]

12. Dagdougui, H.; Ouammi, A.; Sacile, R. Optimal Control of a Network of Power Microgrids Using the Pontryagin's Minimum Principle. IEEE Trans. Control. Syst. Technol. 2014, 22, 1942-1948. [CrossRef]

13. Nutkani, I.U.; Loh, P.C.; Wang, P.; Jet, T.K.; Blaabjerg, F. Intertied ac-ac microgrids with autonomous power import and export. Int. J. Electr. Power Energy Syst. 2015, 65, 385-393. [CrossRef]

14. Goyal, M.; Ghosh, A. Microgrids interconnection to support mutually during any contingency. Sustain. Energy Grids Netw. 2016, 6, 100-108. [CrossRef]

15. John, B.; Ghosh, A.; Goyal, M.; Zare, F. A DC Power Exchange Highway Based Power Flow Management for Interconnected Microgrid Clusters. IEEE Syst. J. 2019, 13, 3347-3357. [CrossRef]

16. Bullich-Massague, E.; Díaz-González, F.; Aragüés-Peñalba, M.; Girbau-Llistuella, F.; Olivella-Rosell, P.; Sumper, A. Microgrid clustering architectures. Appl. Energy 2018, 212, 340-361.

17. Zou, H.; Mao, S.; Wang, Y.; Zhang, F.; Chen, X.; Cheng, L. A Survey of Energy Management in Interconnected Multi-Microgrids. IEEE Access 2019, 7, 72158-72169. [CrossRef]

18. Minciardi, R.; Sacile, R. Optimal Control in a Cooperative Network of Smart Power Grids. IEEE Syst. J. 2011, 6, 126-133. [CrossRef]

19. Zhang, Y.; Xie, L.; Ding, Q. Interactive Control of Coupled Microgrids for Guaranteed System-Wide Small Signal Stability. IEEE Trans. Smart Grid 2015, 7, 1088-1096. [CrossRef]

20. Pashajavid, E.; Shahnia, F.; Ghosh, A. Provisional internal and external power exchange to support remote sustainable microgrids in the course of power deficiency. IET Gener. Transm. Distrib. 2017, 11, 246-260. [CrossRef]

21. Ferdous, S.M.; Shahnia, F.; Shafiullah, G. Provisional Energy Transaction Management amongst Neighboring Microgrids through a DC Power Exchange Link. In Proceedings of the 2019 9th International Conference on Power and Energy Systems (ICPES), Perth, WA, Australia, 10-12 December 2019; pp. 1-6.

22. Ferdous, S.; Shahnia, F.; Shafiullah, G. Provisional energy transaction management amongst neighbouring microgrids through a DC power exchange link. IET Power Electron. 2020, 13, 4129-4139. [CrossRef]

23. Ferdous, S.; Shahnia, F.; Shafiullah, G. Realizing a System of Coupled Microgrids using a Single-phase AC Power Exchange Link. In Proceedings of the 2019 9th International Conference on Power and Energy Systems (ICPES), Perth, WA, Australia, 10-12 December 2019; pp. 1-6.

24. Ferdous, S.M.; Shahnia, F.; Shafiullah, G. Realizing a system of coupled microgrid networks using single-phase interconnection lines. IET Smart Grid 2021. [CrossRef]

25. Ferdous, S.M.; Shahnia, F.; Shafiullah, G. Power Sharing and Control Strategy for Microgrid Clusters. In Proceedings of the 2019 9th International Conference on Power and Energy Systems (ICPES), Perth, WA, Australia, 10-12 December 2019; pp. 1-5.

26. Loh, P.C.; Li, D.; Chai, Y.K.; Blaabjerg, F. Autonomous Operation of Hybrid Microgrid With AC and DC Subgrids. IEEE Trans. Power Electron. 2013, 28, 2214-2223. [CrossRef]

27. Nutkani, I.U.; Loh, P.C.; Blaabjerg, F. Distributed Operation of Interlinked AC Microgrids with Dynamic Active and Reactive Power Tuning. IEEE Trans. Ind. Appl. 2013, 49, 2188-2196. [CrossRef] 
28. Nikolakakos, I.P.; Zeineldin, H.H.; El Moursi, M.; Hatziargyriou, N.D. Stability Evaluation of Interconnected Multi-Inverter Microgrids Through Critical Clusters. IEEE Trans. Power Syst. 2016, 31, 3060-3072. [CrossRef]

29. Ferdous, S.M.; Shafiullah, G.M.; Shahnia, F.; Elavarasan, R.M.; Subramaniam, U. Dynamic Frequency and Overload Management in Autonomous Coupled Microgrids for Self-Healing and Resiliency Improvement. IEEE Access 2020, 8, 116796-116811. [CrossRef]

30. Li, Y.; Gao, D.W.; Gao, W.; Zhang, H.; Zhou, J. A Distributed Double-Newton Descent Algorithm for Cooperative Energy Management of Multiple Energy Bodies in Energy Internet. IEEE Trans. Ind. Inform. 2021, 17, 5993-6003. [CrossRef]

31. Zhang, N.; Sun, Q.; Wang, J.; Yang, L. Distributed adaptive dual control via consensus algorithm in the energy internet. IEEE Trans. Ind. Inform. 2021, 17, 4848-4860.

32. Li, Y.; Gao, W.; Yan, W.; Huang, S.; Wang, R.; Gevorgian, V.; Gao, D. Data-driven Optimal Control Strategy for Virtual Synchronous Generator via Deep Reinforcement Learning Approach. J. Mod. Power Syst. Clean Energy 2021, 9, 919-929. [CrossRef]

33. Majumder, R. Aggregation of microgrids with DC system. Electr. Power Syst. Res. 2014, 108, 134-143. [CrossRef]

34. Ferdous, S.; Shahnia, F.; Shafiullah, G. Various Structures and Control Strategies for Provisional Energy Transaction Management in Coupled Microgrid Clusters. In Proceedings of the 2020 Intermountain Engineering, Technology and Computing (IETC), Orem, UT, USA, 2-3 October 2020; pp. 1-6.

35. Planas, E.; Andreu, J.; Garate, J.I.; de Alegría, I.M.; Ibarra, E. AC and DC technology in microgrids: A review. Renew. Sustain. Energy Rev. 2015, 43, 726-749. [CrossRef]

36. Justo, J.J.; Mwasilu, F.; Lee, J.; Jung, J.-W. AC-microgrids versus DC-microgrids with distributed energy resources: A review. Renew. Sustain. Energy Rev. 2013, 24, 387-405. [CrossRef]

37. Beheshtaein, S.; Cuzner, R.; Savaghebi, M.; Guerrero, J. Review on microgrids protection. IET Gener. Transm. Distrib. 2019, 13, 743-759. [CrossRef]

38. Kim, J.-W.; Choi, H.-S.; Cho, B.H. A novel droop method for converter parallel operation. IEEE Trans. Power Electron. 2002, 17, 25-32. [CrossRef]

39. Augustine, S.; Mishra, M.K.; Lakshminarasamma, N. Adaptive Droop Control Strategy for Load Sharing and Circulating Current Minimization in Low-Voltage Standalone DC Microgrid. IEEE Trans. Sustain. Energy 2015, 6, 132-141. [CrossRef]

40. Shahnia, F.; Chandrasena, R.P.; Rajakaruna, S.; Ghosh, A. Primary control level of parallel distributed energy resources converters in system of multiple interconnected autonomous microgrids within self-healing networks. IET Gener. Transm. Distrib. 2014, 8, 203-222. [CrossRef]

41. Yazdani, A.; Iravani, R. Voltage-Sourced Converters in Power Systems: Modeling, Control, and Applications; Wiley-Blackwell: Hoboken, NJ, USA, 2010.

42. Yazdani, A.; Iravani, R. An accurate model for the dc-side voltage control of the neutral point diode clamped converter. IEEE Trans. Power Deliv. 2005, 21, 185-193.

43. Ferdous, S.M.; Shafiullah, G.M.; Oninda, M.A.M.; Shoeb, A.; Jamal, T. Close loop compensation technique for high performance MPPT using ripple correlation control. In Proceedings of the 2017 Australasian Universities Power Engineering Conference (AUPEC), Melbourne, VIC, Australia, 19-22 November 2017; pp. 1-6.

44. Hosseinimehr, T.; Ghosh, A.; Shahnia, F. Cooperative control of battery energy storage systems in microgrids. Int. J. Electr. Power Energy Syst. 2017, 87, 109-120. [CrossRef]

45. Hosseinimehr, T.; Shahnia, F.; Ghosh, A. Power sharing control of batteries within autonomous microgrids based on their state of charge. In Proceedings of the 2015 Australasian Universities Power Engineering Conference (AUPEC), Wollongong, NSW, Australia, 27-30 September 2015; pp. 1-6.

46. Shahnia, F.; Arefi, A. Eigenanalysis-based small signal stability of the system of coupled sustainable microgrids. Int. J. Electr. Power Energy Syst. 2017, 91, 42-60. [CrossRef]

47. Kunwar, A.; Shahnia, F.; Bansal, R.C. Eigenvalue-Oriented Dynamic Stability Examination to Enhance Designing a Microgrid Hosting Clusters of Inertial and Non-Inertial Distributed Generators. IEEE Trans. Smart Grid 2020, 11, 1942-1955. [CrossRef] 